\title{
Article \\ Benchmark Numerical Model for Progressive Collapse Analysis of RC Beam-Column Sub-Assemblages
}

\author{
Bilal El-Ariss ${ }^{1, * \mathbb{C}}$, Said Elkholy ${ }^{1,2}$ and Ahmed Shehada ${ }^{1}$ \\ 1 Civil and Environmental Engineering Department, United Arab Emirates University, \\ Al Ain 15551, United Arab Emirates; selkhouly@uaeu.ac.ae (S.E.); 201970261@uaeu.ac.ae (A.S.) \\ 2 Civil Engineering Department, Fayoum University, Faiyum 63514, Egypt \\ * Correspondence: bilal.elariss@uaeu.ac.ae
}

Citation: El-Ariss, B.; Elkholy, S.; Shehada, A. Benchmark Numerical Model for Progressive Collapse Analysis of RC Beam-Column

Sub-Assemblages. Buildings 2022, 12, 122. https://doi.org/10.3390/

buildings12020122

Academic Editor: Alessandra Aprile

Received: 27 November 2021

Accepted: 23 January 2022

Published: 25 January 2022

Publisher's Note: MDPI stays neutral with regard to jurisdictional claims in published maps and institutional affiliations.

Copyright: (C) 2022 by the authors. Licensee MDPI, Basel, Switzerland. This article is an open access article distributed under the terms and conditions of the Creative Commons Attribution (CC BY) license (https:// creativecommons.org/licenses/by/ $4.0 /)$.

\begin{abstract}
The pertinence of the fiber element approach to enable thorough numerical investigation on the potential for progressive collapse of reinforced concrete $(\mathrm{RC})$ frame structures owing to interior column exclusion is examined using twenty-nine RC sub-assemblages with five different test setups and three different test scales. A qualitative examination of the results reveals a good agreement between the test results and the outcomes of the fiber-element-based numerical model using the finite element package SeismoStruct. Moreover, minor discrepancies between the test and numerical data demonstrate the capability of the fiber-element-based model to accurately simulate the behavior of $\mathrm{RC}$ elements with various boundary conditions and scales under the context of progressive collapse. Given the costly nature of experimental research, test errors, and the lengthy testing process, the proposed numerical model based on the fiber element approach can be considered a viable option for analyzing structures under progressive collapse due to the interior column exclusion scenario. Engineers and researchers can use the conclusions and comments highlighted in the study as a guide to create accurate models for the analysis of RC structures subjected to progressive collapse.
\end{abstract}

Keywords: progressive collapse; fiber-element-based model; numerical simulation; RC sub-assemblages; column removal

\section{Introduction}

The severe damage caused by structural progressive collapse has increased research activities that focus on structural behavior prediction. The purpose of an experimental work carried out by Qiang et al. [1] was to undertake an experimental validation and analysis of progressive collapse behaviors of RC frames with unique kinked rebar configurations. The study verified that using kinked rebar configuration can improve the structure progressive collapse resistance. Alogla et al. [2] described a mitigating system to improve the structure progressive collapse capacity by using extra steel bars in the middle layer of the beams. The proposed system significantly enlarged the ductility of the specimens. Kang and Tan [3] experimentally examined the progressive collapse behavior of four precast concrete beamcolumn sub-assemblage specimens with $90^{\circ}$ bend or lap-spliced bottom reinforcement in the beam-column joint. The study showed that the improvement of compression arch action and catenary action depended primarily on the detailing. Yu and Tan [4] tested six RC beam-column sub-assemblage specimens to investigate alternate load paths to alleviate progressive collapse. Test outcomes showed that compression arch action is effective in short span beams with low reinforcement ratio, while the catenary action is more active in large span beams with high reinforcement ratio. Specimens tested by Yu and Tan [5] had a special detailing design enhance the catenary action capability at big deformations due to column removal. Additional reinforcement layer at the specimen mid height section with partially unbonded bottom reinforcing bars in the joint region were added. More tests were recommended to better investigate the effect of detailing on the progressive collapse behavior. Rashidian et al. [6] experimentally studied the impacts of 
transverse beams on the frame resistance to progressive collapse. The findings showed an overall improvement in the progressive collapse resistance, with a particular focus on the transverse beam flexural capacity. Furthermore, the transverse beam appeared to restrict the rotation of the middle joint, resulting in additional ductile behavior. Many more tests have been conducted to determine how resistant structures are to progressive collapse. Nevertheless, the existing tests have focused mostly on beams, plane frames, and beam-column substructures [7-9]. In comparison to typical RC framed structures, various structural systems and components, such as precast construction and pre-stressed concrete structures, receive less attention in the analysis of progressive collapse. The knowledge in this domain is restricted to a few studies, so more attention should be devoted to the progressive collapse analysis of such systems $[10,11]$. To explore the RC sub-assemblage structural behavior of, and the development of, alternate load path mechanisms during progressive collapse, Ahmadi et al. [12] tested scaled RC beam-column sub-assemblages in a quasi-static loading.

As experimental testing of progressive collapse are time-demanding and costly, numerical and analytical models have been developed as viable options to resolve such issues and have gradually become the attention of research recently. Gross et al. [13] performed one of the earliest analytical studies on structural progressive collapse. This study presented computer software capable of analyzing and tracing the performance of framed structures during progressive collapse. Casciati et al. [14] investigated seismic reliability in a progressive collapse of 2D reinforced concrete framed structures. Simulating progressive collapse, with simple models rather than sophisticated analysis, has been advocated in a number of recent research. For modeling bar breakage in RC frame structures, Sasani et al. [15] developed in depth models. Tsai et al. [16] used the static linear analysis approach specified by the US General Service Administration (GSA) [17] to conduct a progressive collapse analysis. In their numerical examination, Rashidian et al. [6] proposed 2D and 3D models to evaluate the progressive collapse behavior of scaled RC sub-assemblages. The usage of the Dynamic Amplification Factor (DAF) was employed in inelastic dynamic progressive collapse analyses, as highlighted in DoD and GSA [17,18] guidelines, as well as in works by Grierson et al. and Mohajeri et al. $[19,20]$. With some simplifications, a non-linear static analysis was utilized to analyze pertinent dynamic effects in the investigations of Izzuddin et al., Powell, Vlassis, Marjanishvili et al., and Alashker et al. [21-25]. Ellingwood et al. [26] used the energy balance of interior and exterior forces to analyze progressive collapse. Luccioni et al. [27] employed comprehensive models to investigate structural breakdown of an existing RC structure due to a blast loading. Talaat et al. [28] generated a method using simplified models for simulating structural collapse of RC structures under seismic loading. To test the severe load behavior of steel sub-assemblages in progressive collapse, pre-Northridge connections were considered and studied [29]. Kwasniewski [30] used the GSA guidelines and non-linear finite element simulations to investigate the progressive collapse response of an eight-story building subjected to explosive loading. Hao et al. [31] and Shi et al. [32] also employed explosive loads in their studies and proposed a new methodology for analyzing the behavior of RC frames under the progressive collapse scenario. Elkholy and El-Ariss [33-36] as well as El-Ariss and Elkholy [37] presented a system and modeling algorithm for strengthening RC statically indeterminate beams to resist progressive collapse due to internal column failure. External unbounded unstressed straight wires attached to the beam at deviator and anchorage locations were proposed as part of the technique. The proposed method improved the ultimate load-carrying capacity and energy-dissipation capabilities of the beam. Utilizing the fiber element technique, Shehada et al. [38] numerically examined the resistance of RC framed structures to progressive collapse due to column exclusion. The numerical results from the fiber element technique were compared to a database of 10 previously published tests of RC structures. In a study to simulate the inelastic dynamic response of RC buildings exposed to column failure, Brunesi and Nascimbene [39] detailed a numerical model using an open source fiber-based code, such as OpenSees and SeismoStruct, and verified it by comparison 
with a general purpose FE package, Ls-Dyna. Inelastic force-based fiber elements with five integration points accommodated for both geometric and material nonlinearities in the fiber-based model. A separate purpose routine was derived to simulate the abrupt column removal in OpenSees and SeismoStruct, and the tangent-stiffness-based Rayleigh damping was assumed in the inelastic dynamic analyses. Sousa et al. [40] used the FE program SeismoStruct to numerically assess the nonlinear static and nonlinear dynamic responses of an experimentally tested three-story RC building with plan irregularity. The conclusion was that the infill panels considerably increase the structure initial stiffness and strength, and that modeling the slab should be given extra attention because it may impose artificial beam strengthening.

The above literature review of experimental and numerical studies on the progressive collapse analysis of structures with failed interior column demonstrates that researchers have typically carried out costly experimental testing and/or developed time consuming, sophisticated finite element numerical models for their test structures. Given the costly nature of experimental testing, possible test errors, and the lengthy testing process, numerical models can be a viable alternative to experimental testing. However, due to the scarcity of a comprehensive outline of the available finite element numerical models, this study aims at utilizing a large database of twenty-nine tests of RC sub-assemblages to propose a simple fiber-element-based numerical model to be used by engineers and researchers as a benchmark model for an accurate progressive collapse analysis of RC structures due to interior column removal.

\section{Descriptions of Reference Specimens and Test Setups}

\subsection{Details of Sub-Assemblage Test Specimens}

Figure 1 shows a typical detailing of the RC sub-assemblage reference test specimens considered in this study. A total of twenty-nine sub-assemblage reference test specimens with three different scales were selected from twelve different experimental investigations [1-12]. Table 1 shows the dimensions, reinforcement ratios, and material properties of the scaled RC sub-assemblage specimens. More information can be found in the literature [1-12].

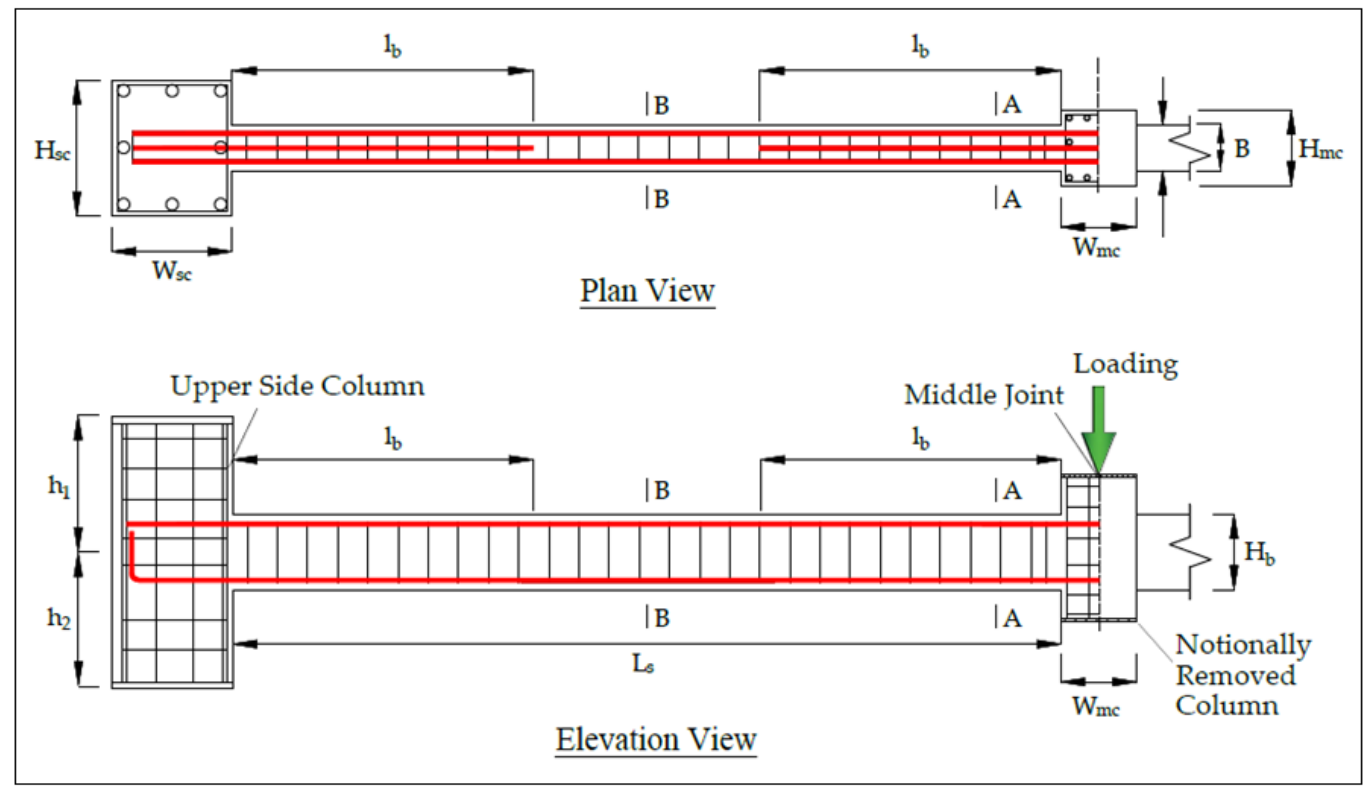

Figure 1. Typical RC beam-column sub-assemblage detailing.

\subsection{Sub-Assemblage Test Setup}

The test specimens considered in this study from various experimental investigations have five different test setups with various boundary conditions. This study labels the 
different setups as setup A, B, C, D, and E and describes their boundary conditions as illustrated in Table 2 and in Figure 2. Moreover, the specimen-generated numerical models with the different boundary conditions are displayed in Figure 2.

Table 1. Specimen details (dimension symbols in the heading row are shown in Figure 1).

\begin{tabular}{|c|c|c|c|c|c|c|c|c|c|c|c|c|c|c|}
\hline \multirow{2}{*}{$\#$} & \multirow{2}{*}{ 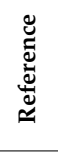 } & \multirow{2}{*}{ 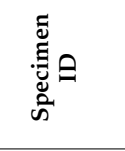 } & \multirow[b]{2}{*}{ Scale } & \multirow{2}{*}{$\begin{array}{c}\mathrm{L}_{\mathrm{s}} \\
(\mathrm{mm})\end{array}$} & \multirow{2}{*}{$\begin{array}{c}l_{b} \\
(\mathrm{~mm})\end{array}$} & \multirow{2}{*}{$\begin{array}{c}\mathrm{h}_{1} \\
(\mathrm{~mm})\end{array}$} & \multirow{2}{*}{$\begin{array}{c}\mathrm{h}_{2} \\
(\mathrm{~mm})\end{array}$} & \multicolumn{3}{|c|}{ Cross Section Dimension $(\mathrm{mm} \times \mathbf{m m})$} & \multirow{2}{*}{$\begin{array}{c}\rho_{\text {top }} \text { at } \\
\text { Section } \\
\text { A-A (\%) }\end{array}$} & \multirow{2}{*}{$\begin{array}{c}\rho_{\text {bot at }} \\
\text { Section } \\
\text { A-A (\%) }\end{array}$} & \multirow{2}{*}{$\begin{array}{l}f_{c}^{\prime} \text { for } \\
\text { Beam } \\
\text { (MPa) }\end{array}$} & \multirow{2}{*}{$\begin{array}{l}f_{y} \text { for } \\
\text { Beam } \\
(\mathrm{MPa})\end{array}$} \\
\hline & & & & & & & & $\begin{array}{c}\text { Beam } \\
\mathbf{H}_{\mathrm{b}} \times \mathbf{B}\end{array}$ & $\begin{array}{c}\text { Side } \\
\text { Column } \\
\mathbf{H}_{\mathrm{sc}} \times \mathbf{W}_{\mathrm{sc}}\end{array}$ & $\begin{array}{c}\text { Mid- } \\
\text { Column } \\
\mathrm{H}_{\mathrm{mc}} \times \mathbf{W}_{\mathrm{mc}}\end{array}$ & & & & \\
\hline 1 & [1] & $\mathrm{RCB}$ & $1 / 3$ & 1900 & 664 & 185 & 185 & $170 \times 85$ & $\mathrm{~N} / \mathrm{A} \times 500$ & $200 \times 200$ & 0.92 & 0.72 & 43.1 & 387 \\
\hline 2 & \multirow{4}{*}{ [2] } & SS-1 & $1 / 2$ & 2750 & 900 & 450 & 450 & $250 \times 150$ & $400 \times 400$ & $250 \times 250$ & 0.45 & 0.45 & 26.8 & 510 \\
\hline 3 & & SS-2 & $1 / 2$ & 2750 & 900 & 450 & 450 & $250 \times 150$ & $400 \times 400$ & $250 \times 250$ & 0.45 & 0.45 & 26.8 & 510 \\
\hline 4 & & SS-3 & $1 / 2$ & 2750 & 900 & 450 & 450 & $250 \times 150$ & $400 \times 400$ & $250 \times 250$ & 0.45 & 0.45 & 27.5 & 510 \\
\hline 5 & & SS-4 & $1 / 2$ & 2750 & 900 & 450 & 450 & $250 \times 150$ & $400 \times 400$ & $250 \times 250$ & 0.45 & 0.45 & 27.5 & 510 \\
\hline 6 & \multirow{2}{*}{ [3] } & MJ-B-S & $1 / 2$ & 2750 & 900 & 450 & 450 & $300 \times 150$ & $\mathrm{~N} / \mathrm{A}$ & $250 \times 250$ & 0.55 & 0.37 & $27.9 / 35.8$ & 462 \\
\hline 7 & & MJ-L-S & $1 / 2$ & 2750 & 900 & 450 & 450 & $300 \times 150$ & $\mathrm{~N} / \mathrm{A}$ & $250 \times 250$ & 0.55 & 0.37 & $27.9 / 35.8$ & 462 \\
\hline 8 & \multirow{5}{*}{ [4] } & S4 & $1 / 2$ & 2750 & 1000 & 450 & 450 & $250 \times 150$ & $450 \times 400$ & $250 \times 250$ & 1.24 & 0.82 & 38.2 & 494 \\
\hline 9 & & S5 & $1 / 2$ & 2750 & 1000 & 450 & 450 & $250 \times 150$ & $450 \times 400$ & $250 \times 250$ & 1.24 & 1.24 & 38.2 & 494 \\
\hline 10 & & S6 & $1 / 2$ & 2750 & 1000 & 450 & 450 & $250 \times 150$ & $450 \times 400$ & $250 \times 250$ & 1.87 & 0.82 & 38.2 & $494 / 513$ \\
\hline 11 & & S7 & $1 / 2$ & 2150 & 780 & 450 & 450 & $250 \times 150$ & $450 \times 400$ & $250 \times 250$ & 1.24 & 0.82 & 38.2 & 494 \\
\hline 12 & & S8 & $1 / 2$ & 1550 & 560 & 450 & 450 & $250 \times 150$ & $450 \times 400$ & $250 \times 250$ & 1.24 & 0.82 & 38.2 & 494 \\
\hline 13 & \multirow{2}{*}[7]{} & S1 & $1 / 2$ & 2750 & 1000 & 450 & 450 & $250 \times 150$ & $400 \times 400$ & $250 \times 250$ & 0.9 & 0.49 & 31.2 & $511 / 527$ \\
\hline 14 & & S2 & $1 / 2$ & 2750 & 925 & 450 & 450 & $250 \times 150$ & $400 \times 400$ & $250 \times 250$ & 0.73 & 0.49 & 31.2 & 511 \\
\hline 15 & \multirow{6}{*}[9]{} & NSC-8 & $1 / 2$ & 2000 & 700 & $\mathrm{~N} / \mathrm{A}$ & $\mathrm{N} / \mathrm{A}$ & $250 \times 150$ & $400 \times 400$ & $250 \times 250$ & 0.96 & 0.64 & 31.7 & 577 \\
\hline 16 & & NSC-11 & $1 / 2$ & 2750 & 900 & $\mathrm{~N} / \mathrm{A}$ & $\mathrm{N} / \mathrm{A}$ & $250 \times 150$ & $400 \times 400$ & $250 \times 250$ & 0.96 & 0.64 & 31.1 & 577 \\
\hline 17 & & NSC-13 & $1 / 2$ & 3250 & 1100 & N/A & N/A & $250 \times 150$ & $400 \times 400$ & $250 \times 250$ & 0.96 & 0.64 & 30.5 & 577 \\
\hline 18 & & HSC-8 & $1 / 2$ & 2000 & 750 & N/A & $\mathrm{N} / \mathrm{A}$ & $250 \times 150$ & $400 \times 400$ & $250 \times 250$ & 0.96 & 0.64 & 60.5 & 577 \\
\hline 19 & & HSC-11 & $1 / 2$ & 2750 & 900 & $\mathrm{~N} / \mathrm{A}$ & $\mathrm{N} / \mathrm{A}$ & $250 \times 150$ & $400 \times 400$ & $250 \times 250$ & 0.96 & 0.64 & 61.2 & 577 \\
\hline 20 & & HSC-13 & $1 / 2$ & 3250 & 1100 & $\mathrm{~N} / \mathrm{A}$ & $\mathrm{N} / \mathrm{A}$ & $250 \times 150$ & $400 \times 400$ & $250 \times 250$ & 0.96 & 0.64 & 59.3 & 577 \\
\hline 21 & \multirow{2}{*}[5]{} & $\mathrm{F} 1$ & $1 / 2$ & 2750 & 1000 & 1100 & 1050 & $250 \times 150$ & $250 \times 250$ & $250 \times 250$ & 1.15 & 0.77 & 29.69 & $520 / 488$ \\
\hline 22 & & F2 & $1 / 2$ & 2750 & 1000 & 1100 & 1050 & $250 \times 150$ & $250 \times 250$ & $250 \times 250$ & 1.15 & 0.77 & 26.69 & $520 / 488$ \\
\hline 23 & \multirow{3}{*}{ [8] } & IF-B & $1 / 2$ & 2750 & 1000 & 1325 & 1025 & $300 \times 150$ & $250 \times 250$ & $250 \times 250$ & 0.97 & 0.64 & $27.7 / 26.9$ & $553.2 / 593.7$ \\
\hline 24 & & IF-L & $1 / 2$ & 2750 & 1000 & 1325 & 1025 & $300 \times 150$ & $250 \times 250$ & $250 \times 250$ & 0.97 & 0.64 & $27.7 / 26.9$ & $553.2 / 593.7$ \\
\hline 25 & & EF-B & $1 / 2$ & 2750 & 1000 & 1325 & 1025 & $300 \times 150$ & $250 \times 250$ & $250 \times 250$ & 0.97 & 0.64 & $27.7 / 26.9$ & $553.2 / 593.7$ \\
\hline 26 & [6] & $2 \mathrm{D}$ & $3 / 10$ & 1400 & 500 & 520 & 820 & $140 \times 200$ & $200 \times 200$ & $200 \times 200$ & 0.57 & 0.38 & 26 & 530 \\
\hline 27 & [10] & $\mathrm{RC}$ & $1 / 2$ & 2650 & 700 & 1200 & 2300 & $300 \times 200$ & $350 \times 350$ & $500 \times 500$ & 0.88 & 0.88 & 24.7 & 485 \\
\hline 28 & [12] & Prototype & $3 / 10$ & 1500 & 500 & 720 & 820 & $140 \times 200$ & $200 \times 200$ & $200 \times 200$ & 0.39 & 0.39 & 26 & 530 \\
\hline 29 & [11] & MS & $1 / 3$ & 1148 & $\mathrm{~N} / \mathrm{A}$ & 450 & 450 & $135 \times 100$ & $135 \times 135$ & $135 \times 135$ & 0.79 & 0.79 & 25 & 500 \\
\hline
\end{tabular}


Table 2. Types and descriptions of different test setups and boundary conditions.

\begin{tabular}{|c|c|c|c|c|c|c|}
\hline$\#$ & Reference & $\begin{array}{l}\text { Specimen } \\
\text { ID }\end{array}$ & Scale & Reference Findings & $\begin{array}{l}\text { Test } \\
\text { Setup }\end{array}$ & Test Set-Up Description/Boundary Conditions \\
\hline 1 & [1] & $\mathrm{RCB}$ & $1 / 3$ & $\begin{array}{l}\text { The kinked rebar arrangement proposed improves } \\
\text { the progressive collapse resistances of RC. }\end{array}$ & Setup & $\begin{array}{l}\text { - } \quad \text { Restraints at Outer Beam Ends. } \\
\text { - } \quad \text { Fixed Boundary Conditions at Beam Ends. }\end{array}$ \\
\hline 2 & \multirow{4}{*}[2]{} & SS-1 & $1 / 2$ & \multirow{4}{*}{$\begin{array}{l}\text { Concrete beam ductility and collapse load are greatly } \\
\text { improved by the proposed mitigation strategy. }\end{array}$} & \multirow{19}{*}{$\underset{B}{\text { Setup }}$} & \multirow{19}{*}{$\begin{array}{l}\text { Restraints at the Bottom of Lower } \\
\text { Side Columns. } \\
\text { Horizontal Restraints along the Side Columns. } \\
\text { Axial/Horizontal Restraints of Beams with } \\
\text { Tension/Compression Load Cells at Beam } \\
\text { Ends to Measure the Beam Axial/ } \\
\text { Horizontal Reaction. } \\
\text { Rotational and Lateral Restraints of Beams at } \\
\text { and in the Vicinity of Failed Column. } \\
\text { Note: Ref. [9] Has only Axial Restraints } \\
\text { of Beams. }\end{array}$} \\
\hline 3 & & SS-2 & $1 / 2$ & & & \\
\hline 4 & & SS-3 & $1 / 2$ & & & \\
\hline 5 & & SS-4 & $1 / 2$ & & & \\
\hline 6 & \multirow{2}{*}[3]{} & MJ-B-S & $1 / 2$ & \multirow{2}{*}{$\begin{array}{l}\text { Joint details and beam reinforcement ratio have a big } \\
\text { role in improving CAA and catenary } \\
\text { action resistance. }\end{array}$} & & \\
\hline 7 & & MJ-L-S & $1 / 2$ & & & \\
\hline 8 & \multirow{5}{*}{ [4] } & S4 & $1 / 2$ & \multirow{5}{*}{$\begin{array}{l}\text { Both compressive arch action and catenary action } \\
\text { might be enhanced with suitable axial constraints, } \\
\text { greatly boosting structural resistance beyond the } \\
\text { beam flexural limit. }\end{array}$} & & \\
\hline 9 & & S5 & $1 / 2$ & & & \\
\hline 10 & & S6 & $1 / 2$ & & & \\
\hline 11 & & S7 & $1 / 2$ & & & \\
\hline 12 & & S8 & $1 / 2$ & & & \\
\hline 13 & \multirow[t]{2}{*}{ [7] } & S1 & $1 / 2$ & \multirow{2}{*}{$\begin{array}{l}\text { A component-based joint model made up of a } \\
\text { succession of springs was proposed and included } \\
\text { into a macromodel-based finite element analysis that } \\
\text { used fiber elements to model beams. }\end{array}$} & & \\
\hline 14 & & S2 & $1 / 2$ & & & \\
\hline 15 & \multirow{6}{*}{ [9] } & NSC-8 & $1 / 2$ & \multirow{6}{*}{$\begin{array}{l}\text { The use of high-strength concrete was found to } \\
\text { improve the compressive arch action capacity, } \\
\text { particularly for frames with a low span-to-depth } \\
\text { ratio, while lowering the tensile catenary action } \\
\text { capacity at large deformations. }\end{array}$} & & \\
\hline 16 & & NSC-11 & $1 / 2$ & & & \\
\hline 17 & & NSC-13 & $1 / 2$ & & & \\
\hline 18 & & HSC-8 & $1 / 2$ & & & \\
\hline 19 & & HSC-11 & $1 / 2$ & & & \\
\hline 20 & & HSC-13 & $1 / 2$ & & & \\
\hline 21 & \multirow[t]{2}{*}{ [5] } & F1 & $1 / 2$ & \multirow{2}{*}{$\begin{array}{l}\text { Distinct detailing includes adding an extra layer of } \\
\text { reinforcement at the middle of beam sections, in part } \\
\text { debonding bottom reinforcing bars in the joint } \\
\text { location, and positioning partial hinges away from } \\
\text { adjacent joint improve the catenary action capacity } \\
\text { of beams at large deformations. }\end{array}$} & \multirow{5}{*}{ Setup } & \multirow{5}{*}{$\begin{array}{l}\text { - } \quad \text { Restraints at the Bottom of Lower Side Columns. } \\
\text { Horizontal Restraints at Top of the Upper } \\
\text { Columns. } \\
\text { - } \quad \text { Horizontal Restraints at the Outer Ends of Beams. } \\
\text { Horizontal Restraints at Top End of Side Columns. } \\
\text { Axial/Hostraints at the Bottom End of Side Columns. } \\
\text { Tension/Compression Load Cells at Beam Ends } \\
\text { to Measure the Beam Axial/Horizontal Reaction. } \\
\text { Rotational and Lateral Restraints of Beams at } \\
\text { and in the Vicinity of Failed Column. }\end{array}$} \\
\hline 22 & & $\mathrm{~F} 2$ & $1 / 2$ & & & \\
\hline 23 & \multirow{3}{*}{ [8] } & IF-B & $1 / 2$ & \multirow{3}{*}{$\begin{array}{l}\text { In precast concrete frames, lap spliced reinforcing in } \\
\text { the joint facilitated the formation of higher catenary } \\
\text { activity than a } 90^{\circ} \text { bend of beam bottom } \\
\text { reinforcement. Lap-splicing of beam bottom } \\
\text { reinforcement in the joint is recommended to } \\
\text { prevent progressive collapse. }\end{array}$} & & \\
\hline 24 & & IF-L & $1 / 2$ & & & \\
\hline 25 & & EF-B & $1 / 2$ & & & \\
\hline 26 & [6] & $2 \mathrm{D}$ & $3 / 10$ & $\begin{array}{l}\text { Overall improvement in the progressive collapse } \\
\text { resistance as transverse beams appeared to restrict } \\
\text { the rotation of the middle joint. }\end{array}$ & \multirow{3}{*}{$\begin{array}{l}\text { Setup } \\
\text { D }\end{array}$} & \multirow{3}{*}{$\begin{array}{l}\text { - } \quad \text { Restraints at the Bottom of Lower Side Columns. } \\
\text { Horizontal Restraints at Top of the } \\
\text { Upper Columns. } \\
\text { Horizontal Restraints at Top End of } \\
\text { Side Columns. } \\
\text { - Fixed Boundary Conditions at Bottom End of } \\
\text { the Side Columns. } \\
\text { Axial/Horizontal Restraints of Beams with } \\
\text { Tension/Compression Load Cells at Beam } \\
\text { Ends to Measure the Beam Axial/ } \\
\text { Horizontal Reaction. } \\
\text { Lateral Restraints of Beams in the Vicinity of } \\
\text { Failed Column. }\end{array}$} \\
\hline 27 & [10] & $\mathrm{RC}$ & $1 / 2$ & $\begin{array}{l}\text { More attention should be devoted to the progressive } \\
\text { collapse analysis of precast construction and } \\
\text { pre-stressed concrete structures. }\end{array}$ & & \\
\hline 28 & [12] & Prototype & $3 / 10$ & $\begin{array}{l}\text { The beam action mechanisms of the substructures } \\
\text { are greatly increased when the beam height is } \\
\text { increased. it causes an early steel bar fracture and } \\
\text { reduces the catenary action of the sub-assemblage. }\end{array}$ & & \\
\hline 29 & [11] & MS & $1 / 3$ & $\begin{array}{l}\text { More attention should be devoted to the progressive } \\
\text { collapse analysis of precast construction and } \\
\text { pre-stressed concrete structures. }\end{array}$ & $\underset{E}{\text { Setup }}$ & $\begin{array}{l}\text { Restraints/Pin Support at the Top of Upper } \\
\text { Side Columns. }\end{array}$ \\
\hline
\end{tabular}


Specimen test setup and boudary conditions
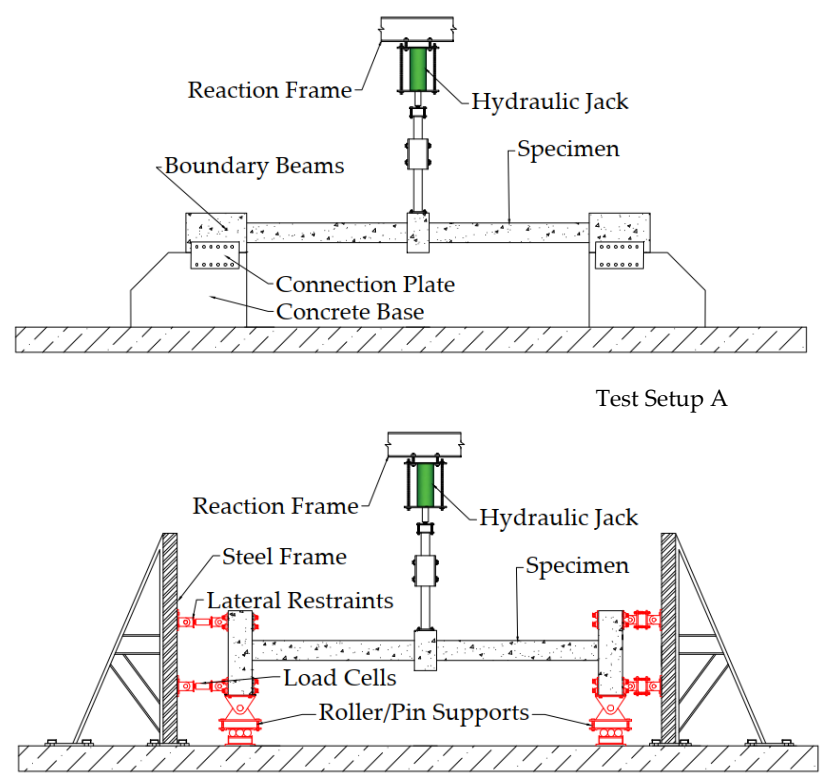

Test Setup B

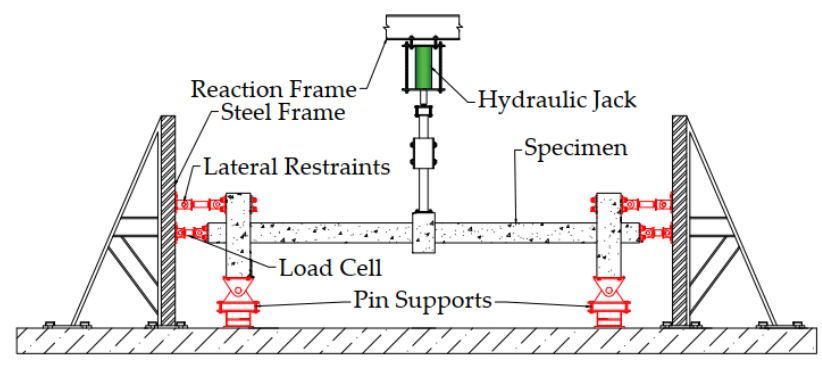

Test Setup C

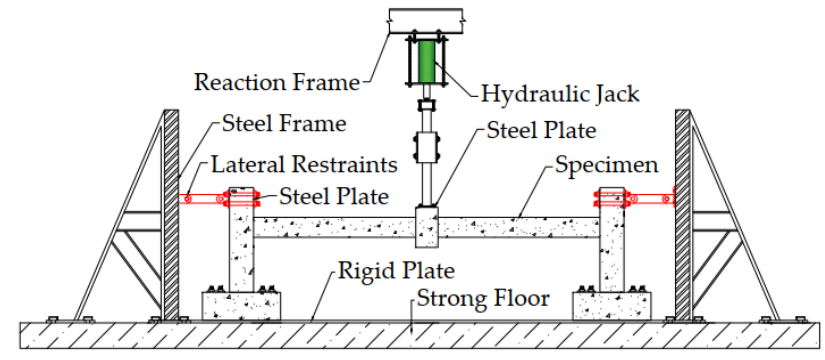

Test Setup D

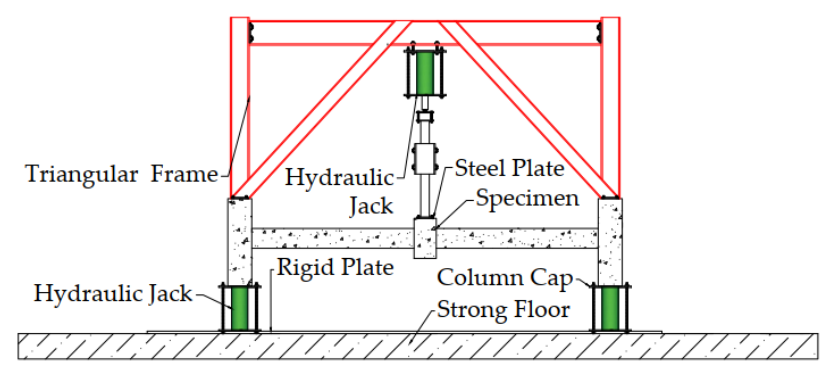

Test Setup E
SeismoStruct model and boundary conditions

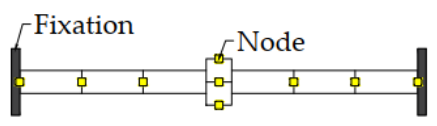

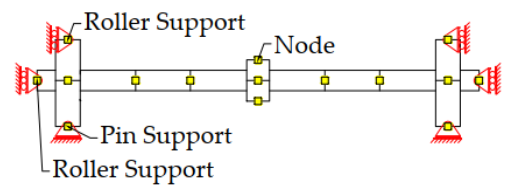
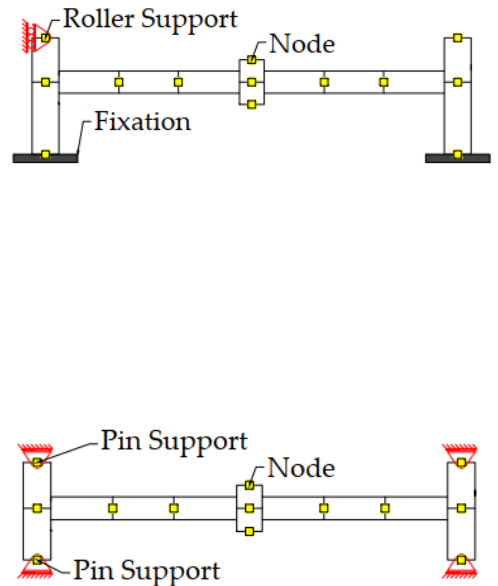

Figure 2. Test setups (as per Table 2) and their corresponding numerically generated models in this study. 


\section{Sensitivity Analysis of Model Key Parameters Using SeismoStruct}

The sensitivity of key parameters impacting the performance of the fiber elementbased numerical model using the finite element package SeismoStruct [41] is studied in this section. This sensitivity study is, however, classified in the following subsections based on the model different key parameters. The key model parameters that were studied and discussed are the element types, concrete material modeling, steel material modeling, number of section fibers, plastic hinge length, number of segments, and boundary conditions of different test setups.

Extensive numerical analyses and simulations, based on the behaviors of the twentynine sub-assemblage test specimens detailed in the previous section, were performed. To achieve the optimal numerical model that accurately simulates the behavior of each test specimen, the consequences of using different material (concrete and steel) modeling, various number of elements, numerous number of section fibers, several plastic hinge lengths, and different boundary conditions on the accuracy of the outcomes of each specimen model were examined and systematized for tuning and calibrating the numerical model to be utilized as a benchmark model in the progressive collapse analysis of RC structures.

\subsection{Element Types}

There are two types of frame fiber element modeling available in SeismoStruct: inealastic force-based plastic-hinge frame elements (infrmFBPH) and inealastic displacementbased plastic-hinge frame elements (infrmDBPH). The two types are founded on distributing the plasticity throughout the element length either by breaking the infrmFBPH element into a number of sections for numerical integration or by defining different nodes and connecting them together in the case of infrmDBPH element. In general, infrmDBPH element shows slower convergence than that of the infrmFBPH element. Therefore, in this study the RC sub-assemblage members were modeled using the infrmFBPH elements.

\subsection{Concrete Material Modeling}

A variety of concrete material models is provided by the software library: Trilinear concrete model (con_tl); Mander nonlinear concrete model (con_ma); Chang-Mander nonlinear concrete model (con_cm); Kappos and Konstantinidis nonlinear concrete model (con_hs); Engineered cementitious composites material (con_ecc); and Kent-Scott-Park concrete model (con_ksp). More information on these models can be found in the SiesmoStruct user manual.

An expanded task of numerically simulating the test behavior of each one of the twenty-nine sub-assemblage test specimens, using the reported test concrete material properties, revealed that the optimal concrete material model to simulate the test behaviors was model con_ma. An example of this expanded simulation task is shown in Figure 3. The figure shows the experimental load-displacement curve of only one specimen, specimen SS-3 [2], and its corresponding numerical load-displacement curves, using the different concrete material models above. It is clear from the figure that most of the concrete material models produced fairly accurate simulations of the test performance, but the most accurate simulation was for the concrete material model con_ma. The same concrete model, con_ma, produced the best simulation of each test behavior of the twenty-eight reference specimens reported in the previous section.

Hence, the model con_ma for concrete was adopted and used throughout this study. Moreover, for this adopted model a strain value between 0.2 and $0.6 \%$ at peak stress as well as an ultimate strain value of $0.7 \%$ were found to be the optimal values for modeling the above reported twenty-nine test specimens, whereas a value between 1.5 and $3.5 \mathrm{MPa}$ proved to be suitable for the concrete tensile strength.

\subsection{Steel Material Modeling}

Like the concrete material, various steel material models are provided by the software library to choose from: bilinear steel model (stl_bl); bilinear steel model with isotropic strain 
hardening (stl_bl2); Menegotto-Pinto steel model (stl_mp); Dodd-Restrepo steel model (stl_dr); Monti-Nuti steel model (stl_mn); Giuffre-Menegotto-Pinto steel model (stl_gmp); and Ramberg-Osgood steel model (stl_ro).

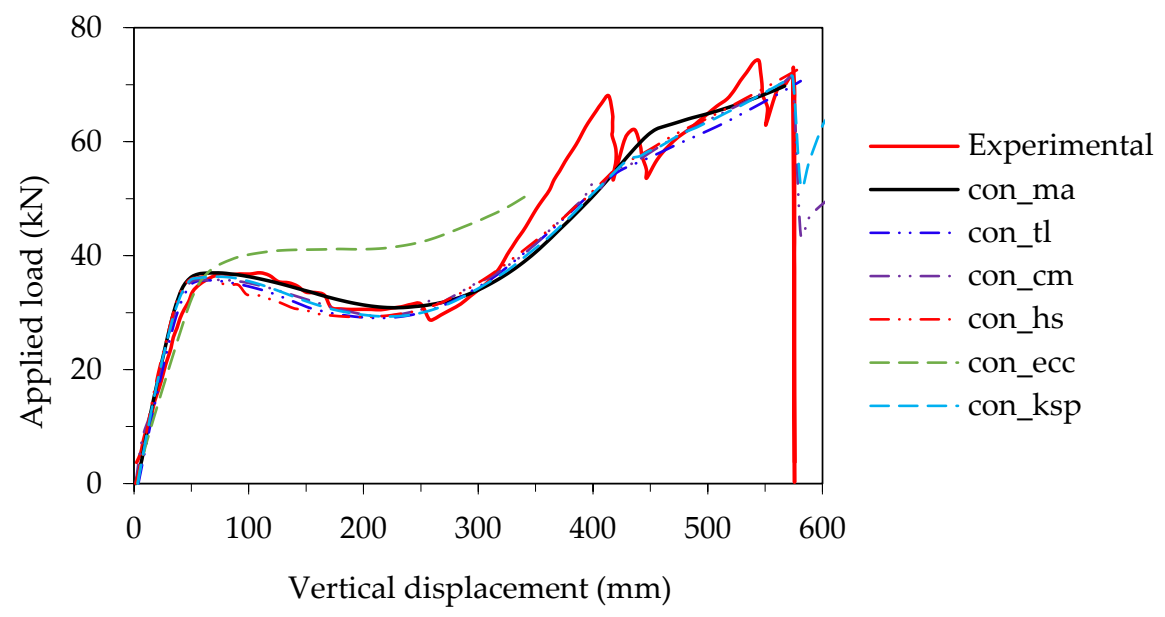

(a)

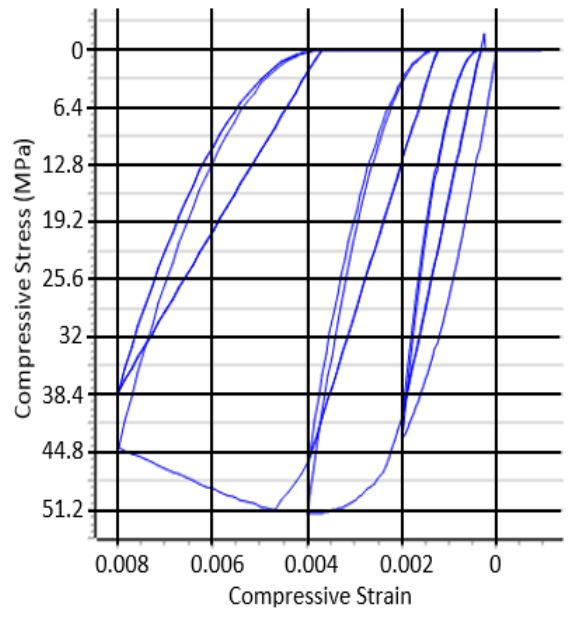

(b)

Figure 3. Test SS-3 [2] and numerical load-displacement curves with concrete material modeling. (a) Applied load versus vertical displacement (at failed column location); (b) Concrete material model con_ma.

Similar to the previous section, and with the concrete material model con_ma being adopted, all the above steel material models were tested in an effort to determine the optimal steel material model that best simulates the test behavior of each one of the twenty-nine test specimens in the previous section. The reported test steel material properties were applied in the models. An example of this effort is presented in Figure 4. The figure shows the experimental load versus displacement curve of one specimen, specimen SS-3 [2], and its corresponding numerical load-displacement curves using the different steel material models above. It can be concluded that all the steel material models produced fairly comparable simulations of the test performance, but the most accurate simulation was for the steel material model stl_mp. The same steel model, stl_mp, produced the best simulation of each one of the other twenty-eight test behaviors.

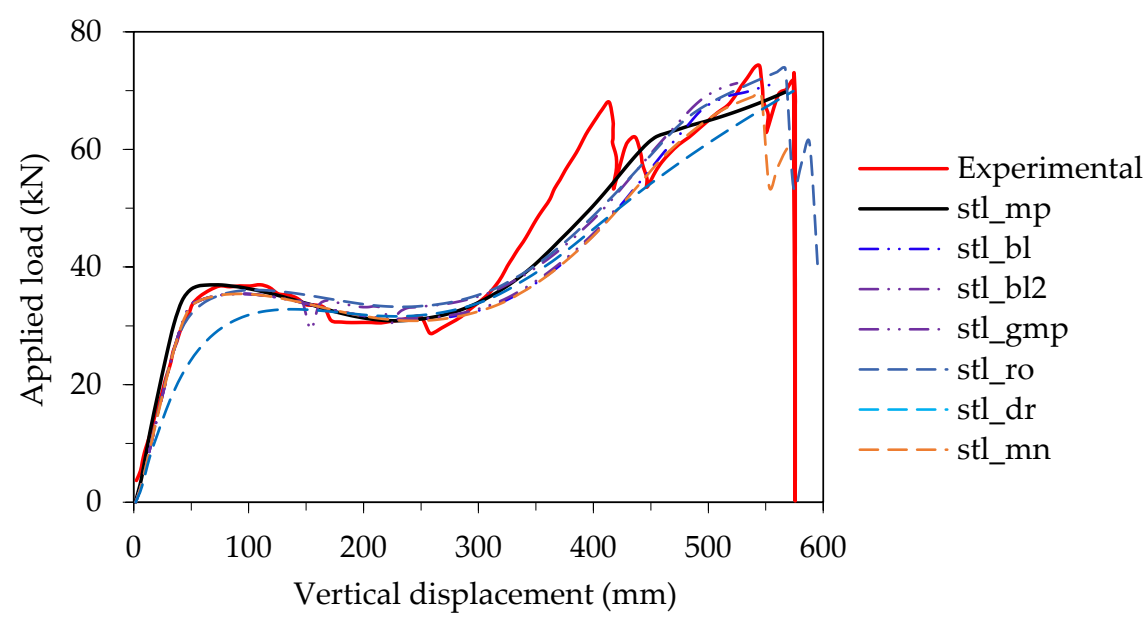

(a)

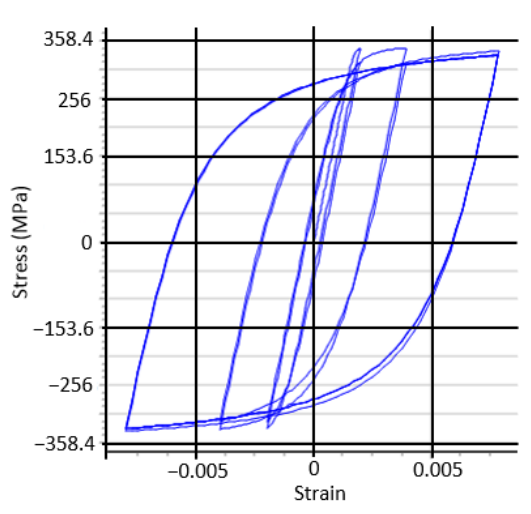

(b)

Figure 4. Test SS-3 [2] and numerical load-displacement curves with various steel material models. (a) Applied load versus vertical displacement (at failed column location); (b) Steel material model stl_mp. 
Hereafter, the model stl_mp for steel was adopted this study. Furthermore, for this adopted model, a strain hardening ratio of $0.5 \%$ and a fracture strain value between 6 and $11 \%$ were found to be appropriate for modeling the twenty-nine test specimens.

Table 3 shows a summary of the input parameters related to the steel bar and concrete materials used in the numerical modeling. The material parameters are extracted from the reported test data and are shown in Table 1. The material parameters that are not provided in the reported test data are taken form the associated references shown in Table 3.

Table 3. Summary of input material parameters in the numerical model.

\begin{tabular}{cc}
\hline Menegotto-Pinto Steel Material Model, stl_mp [42] & Mander et al. Nonlinear Concrete Model, con_ma [43] \\
\hline Modulus of elasticity, $E_{S}(\mathrm{GPa})$ & Compressive strength, $f_{c}(\mathrm{MPa})$ \\
Yield strength, $f_{y}(\mathrm{MPa})$ & Tensile strength, $f_{t}(\mathrm{MPa})$ \\
Strain hardening parameter, $\mu(\mathrm{mm} / \mathrm{mm})$ & Modulus of elasticity, $E_{\mathcal{c}}(\mathrm{GPa})$ \\
Transition curve initial shape parameter, $R_{0}$ & Strain at peak stress, $\varepsilon_{\mathcal{c}}(\mathrm{mm} / \mathrm{mm})$ \\
Transition curve shape calibrating coefficients, $a_{1}$ and $a_{2}$ & Specific weight, $\gamma\left(\mathrm{kN} / \mathrm{m}^{3}\right)$ \\
Isotropic hardening calibrating coefficients, $a_{3}$ and $a_{4}$ & \\
Fracture/buckling strain, $\varepsilon_{u l t}(\mathrm{~mm} / \mathrm{mm})$ & \\
Specific weight, $\gamma\left(\mathrm{kN} / \mathrm{m}^{3}\right)$ & \\
\hline
\end{tabular}

\subsection{Number of Section Fibers}

The RC sub-assemblage members were modeled in this study using the infrmFBPH elements. The member cross-sections are represented by a number of discrete fibers that represent concrete and steel independently. Figure 5 shows the discretization of a representative $\mathrm{RC}$ cross section. Integration of the inelastic stress-strain relationship of the separate fibers yields the cross-section stress-strain state. A two Gauss point nonlinear cubic formulation, which is used to numerically integrate the equations of equilibrium, results in a spread of plasticity along the element.

(i) Unconfined Concrete Fibres

(ii) Confined Concrete Fibres

(iii) Steel Bars Fibres

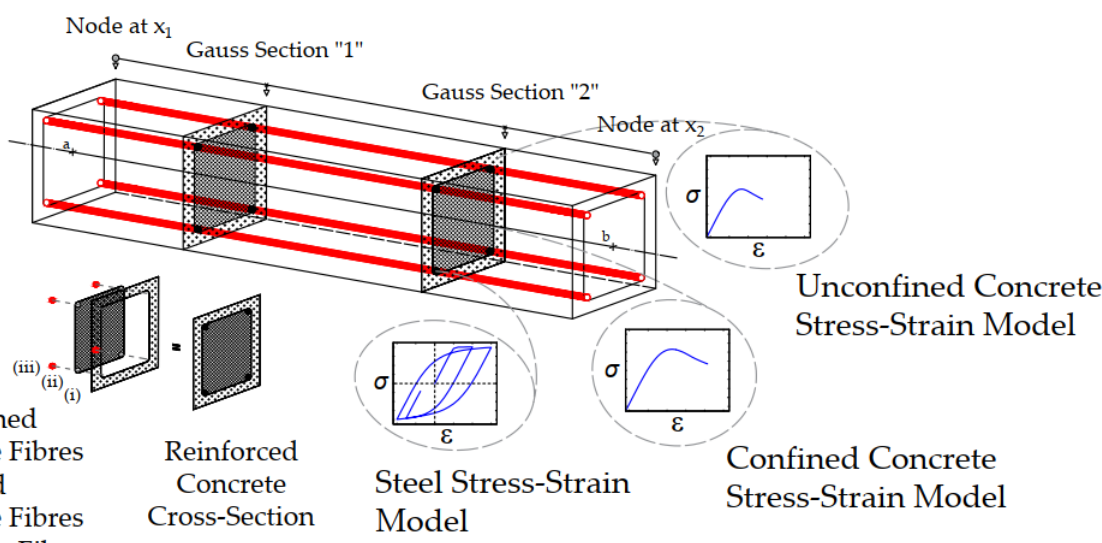

Figure 5. Discretization of the structural element in fiber type modeling.

To examine the effect of the number of section fibers on the accuracy of the numerical results, the discretization of the sub-assemblage members was carried out by dividing the member section into a number of fibers that varied from 29 to 249 fibers, as shown in Figure 6. The adopted material models con_ma and stl_mp were employed in the numerical model. Despite the fact that all the numerical behaviors were close to the test specimen SS-3 behavior [2], Figure 6 demonstrates that when the number of section fibers was 149 the predicted numerical behavior was the most representative of test results. The same conclusion was arrived at when simulating the test behaviors of the other twentyeight specimens. As a result, 149 section fibers were adopted in the model utilized in this study. 

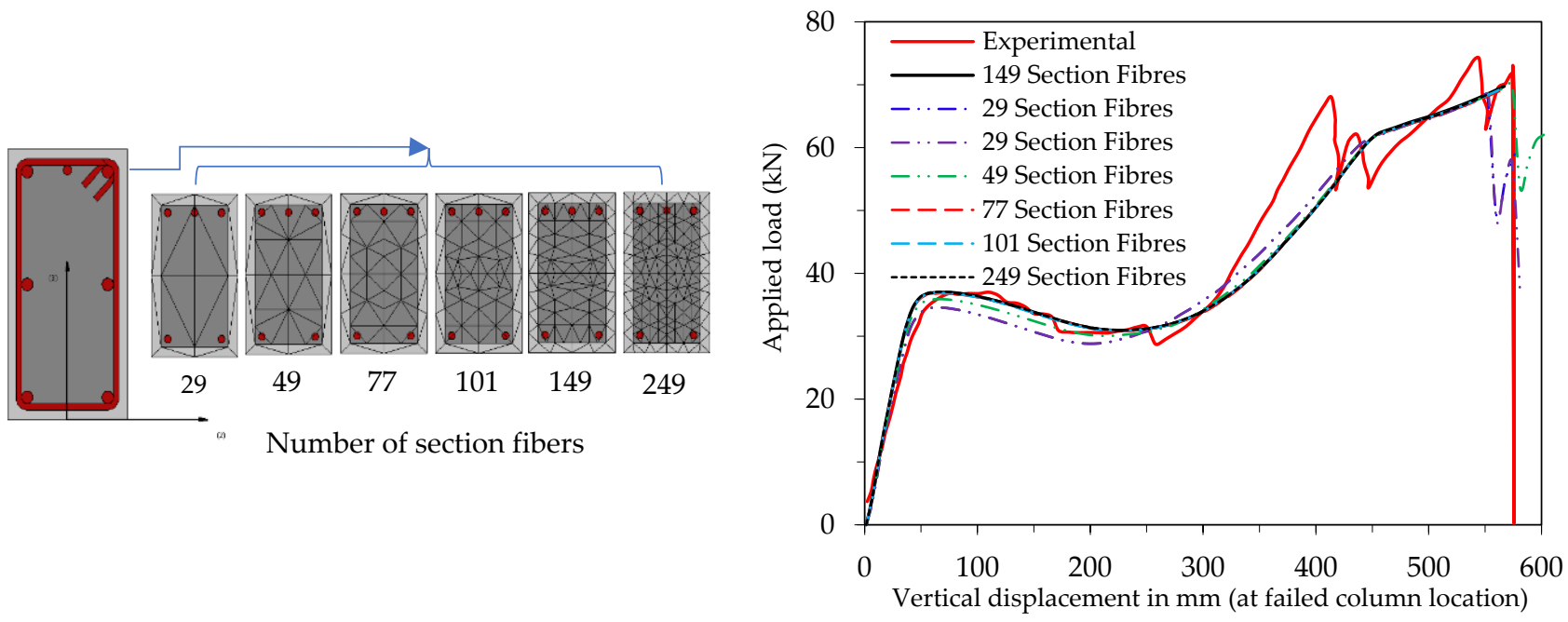

Figure 6. Test SS-3 [2] and numerical load-displacement curves with different numbers of section fibers.

\subsection{Plastic Hinge Length}

Another key model parameter that has an impact of the numerical results is the plastic hinge length. To examine the impact of this parameter on the numerical outcomes, plastic hinge lengths $\left(L_{p}\right)$ of $20,25,35,40,45$, and $50 \%$ of the element length $(L)$ were considered, in addition to the software default length of $16.67 \%$. The material models, con_ma and stl_mp, and number of section fibers, 149, adopted in this study were employed. When compared with the test result of specimen SS-3 [2], Figure 7 shows clearly that the plastic hinge length specified in the model significantly affected the ductility and the capability to predict the catenary action of the test specimen. The software default value of $16.67 \%$ produced the least ductility without capturing the catenary action behavior, whereas the ductility and catenary action improved with the increase in the plastic hinge length, as shown in Figure 7. It can be concluded from the figure that using a plastic hinge length of $50 \%$ of the element length produced the most accurate simulation of test specimen SS-3 [2]. A plastic hinge length of $50 \%$ of the element length was adopted in this study.
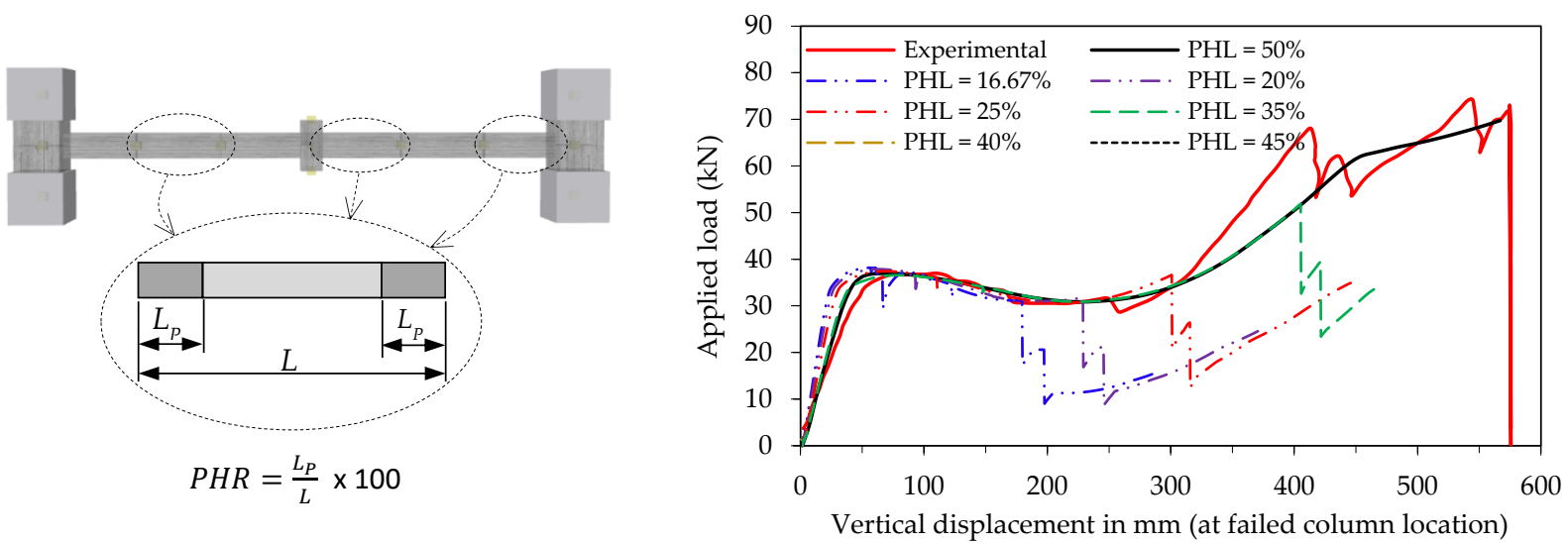

Figure 7. Test SS-3 [2] and numerical load-displacement curves using various plastic hinge lengths, PHL.

\subsection{Number of Segments}

The beams of the sub-assemblage test specimens were modeled by dividing them into a number of segments following their physical cross-section dimensions and reinforcement ratios in their hogging (A-A) and sagging (B-B) regions, as displayed in scheme 1 of Figure 8 . Each segment is identified by one element with constant cross section and reinforcement ratio along the length of the element. In the numerical model, all the above-adopted model 
key parameters were employed, and the generated numerical simulation was in good agreement with the specimen HSC-8 [9] test behavior, as exhibited in Figure 8.

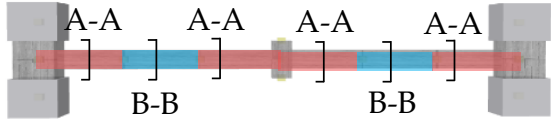

Scheme 1

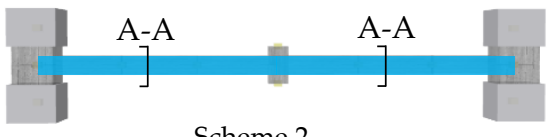

Scheme 2

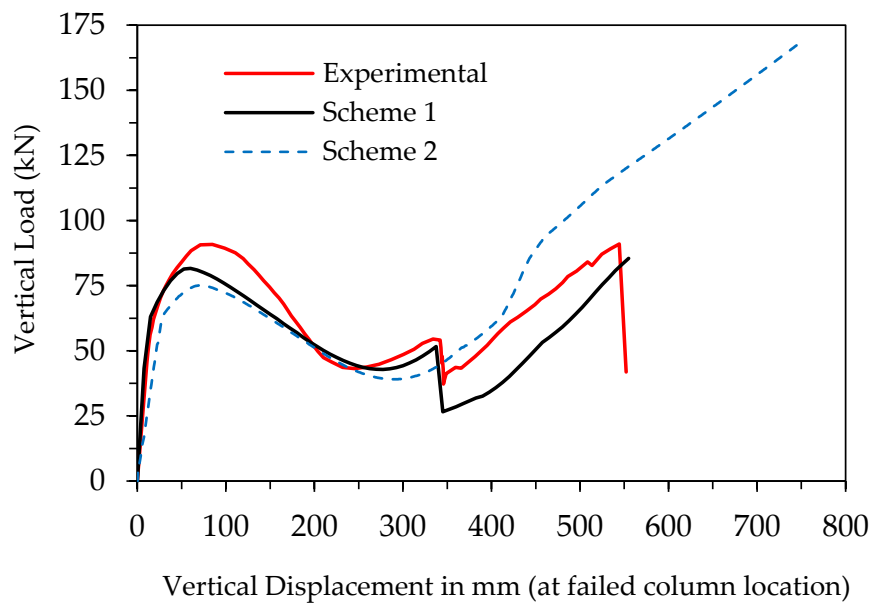

Figure 8. Test HSC-8 [9] and numerical load-displacement curves with different numbers of segments.

In order to verify whether or not the number of segments hah any impact on the numerical results, the same reinforcement ratio, A-A, was assumed in both hogging and sagging regions, and the beam was, therefore, modeled as one segment, as shown in scheme 2 in Figure 8. Scheme 2 established an underestimation of the arch action, overestimation of the catenary action, and more ductile behavior, which were not in agreement with the test results of specimen HSC-8 [9], as shown in Figure 8.

\subsection{Numerical Damage and Failure Detection}

It is advantageous to set numerous limit state criteria in order to detect and identify different types of damages to the structure when subjected to progressive collapse scenario. It is equally critical to recognizing when different damages such as yielding of reinforcement, structural damage, and collapse are reached in the framework of structural performance. These limit states are realized by SeismoStruct and can be set by defining so-called Performance Criteria, which allow the program to automatically monitor the achievement of a certain limit state value (such as cracking in the element, concrete cover spalling, concrete core crushing, yielding of steel, steel fracture, member section curvature, or element chord rotation) throughout the analysis of the structure. The built-in Performance Criteria have limits, in accordance with different design codes, which when reached the corresponding damage is detected and identified in a log file.

Therefore, to further validate the numerical model outcomes using all of the above proposed optimal key parameters, the model was put to test by defining different performance criteria and comparing the predicted, detected different damage types with those observed during the physical testing of specimen SS-3 [2]. Specimen SS-3 was selected for this comparison, since it provided the development sequence of the different physical damage types as the test progressed up to the complete collapse. This comparison is displayed in Figures 9 and 10. In these figures, the instant at which a specific physical test damage was reached is identified by a letter of the alphabet (i.e., A-F); while the instant at which a specific matching numerical damage was reached is labeled as a numeral (i.e., 1-7). Figure 9 clearly shows that the proposed model not only numerically predicted the same type of damage developed in the test specimen but also closely predicted the test instant/load at which the test damage was developed. The schematic different damage types observed in the test and their corresponding model results are identified in Figure 10. From the figure, it can be deduced that the model estimated the test vertical displacement at the removed column location and predicted the experimental formation of flexural cracks, bar yielding, chord rotation, concrete spalling, concrete crushing, and rupture of bars towards 
the beam ends fairly accurately. Only the specimen right end schematic damages are shown in Figure 10.

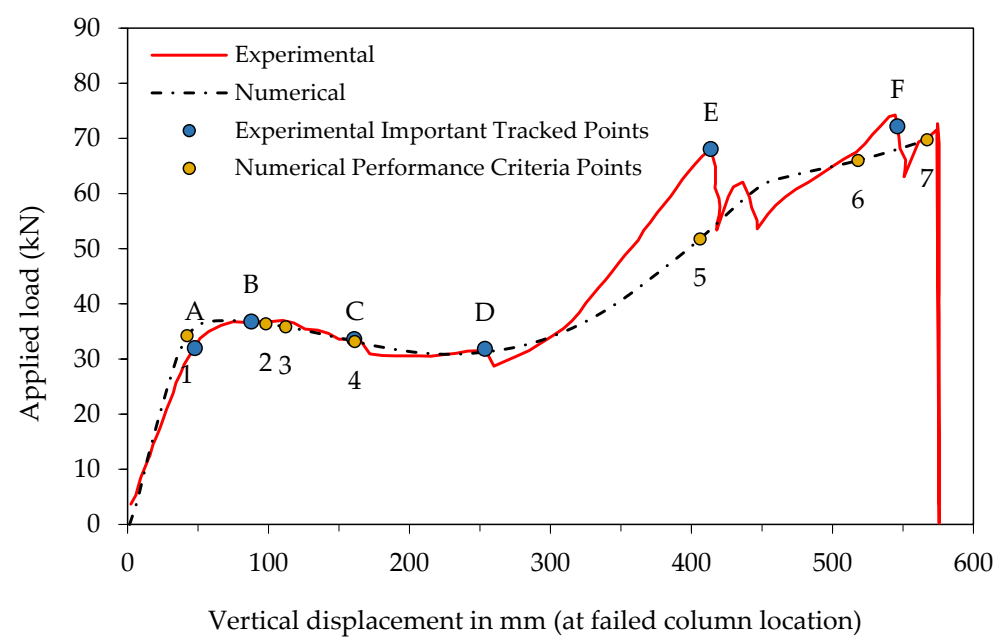

Figure 9. Test SS-3 [2] and numerical load-displacement curves with different performance criteria.
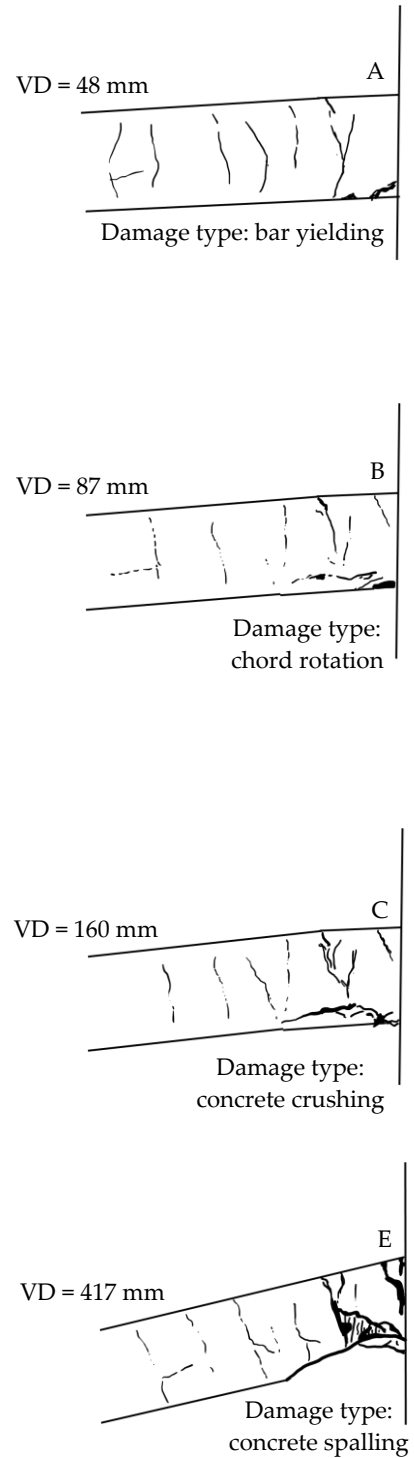

Figure 10. Cont.
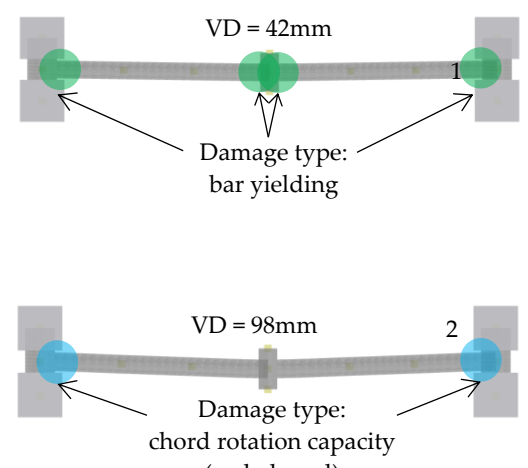

(code-based)

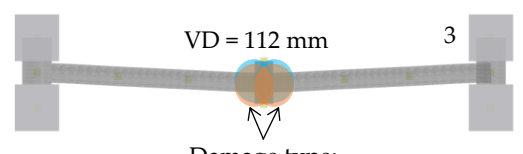

Damage type:

chord rotation rapacity (code-based) and concrete crushing
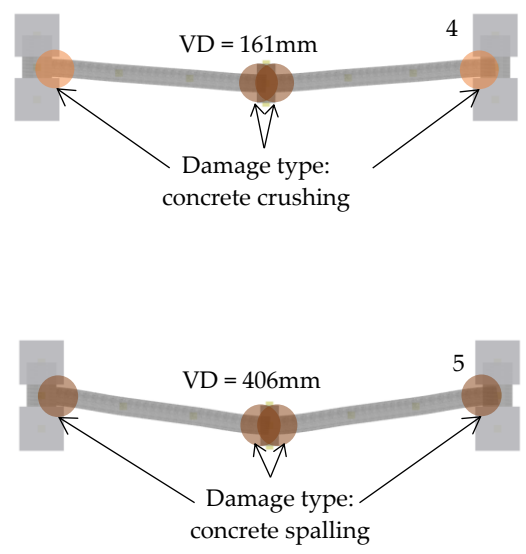


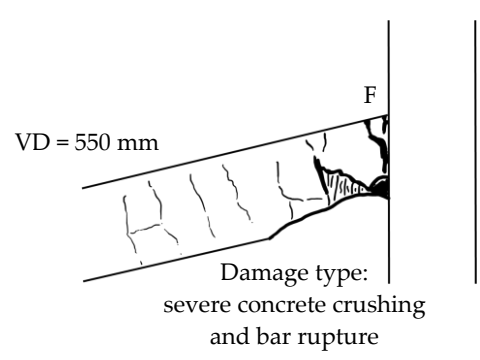

Figure 10. Damage types and sequence in specimen SS-3 [2]: test, left, and numerical predictions, right (letters of the alphabet and numerals are the same as those in Figure 9); VD is the vertical displacement at location of failed column.

Overall, it can be inferred that adopting the optimal key parameters recommended above in the model can produce numerical behaviors that would be in good agreement with their test counterparts.

It should be further noted that the number of elements in each model was low and ranged between 7 and 11 elements, depending on the reinforcement detailing of the specimen. This remarkably low number of elements in the SeismoStruct analysis, when compared with other 2D and 3D numerical methods, is advantageous, as it not only significantly reduces the modeling process, computational running time, and computer storage space but also demonstrates excellent agreement between the numerical and experimental test results.

\subsection{Boundary Conditions of Different Test Setups}

To complement the numerical model verification in this study, the effects of the boundary conditions on the numerical progressive collapse simulation of the twenty-nine test specimens were examined. The various boundary conditions of the considered specimens are described in Table 2 and Figure 2 above. The boundary conditions depend on the specimen support types, i.e., fixation, roller, or pin support and, accordingly, the corresponding degree of freedom in the model was released. As for the interface between different materials, this study assumes the model default full bond interface between the concrete and steel bar. The boundary conditions of the test specimens were simulated, and their effects on the numerical results were plotted in Figure 11, which compares the numerical and test load versus vertical displacement curves of all twenty-nine specimens. In general, the figure shows the high capability of the proposed model to consider different boundary conditions and to predict the flexure action, compression arch action, and tension catenary action of the test results. Figure 11a clearly reveals that simulating the boundary conditions of test setup A produced less numerical ductility but was able to accurately predict the failure load. Figure $11 \mathrm{~b}-\mathrm{t}$ show that simulating the boundary conditions of test setup B produced numerical behaviors that are overall in good agreement with their test counterparts, except for Figure 11f,i,k,q. Figure $11 \mathrm{f}$ demonstrates that the boundary conditions resulted in a more numerical ductile behavior, accompanied with higher numerical failure load than those of the test, whereas Figure 11i,q show less numerical ductility associated with lesser failure load than their test counterparts. It is worth noting that the boundary conditions of setup B appears to have an impact on the simulation where the numerical initial behavior of the specimens were stiffer than those of the experimental results. The boundary conditions of test setups $C$ and $E$ gave accurate numerical simulations of the test behaviors as shown in Figure 11u-y,ac. However, for test setup D, simulating the boundary conditions of one test demonstrated an accurate simulation, Figure 11z, while the other two tests instigated more numerical ductility and accurate numerical failure load when compared with the test results as shown in Figure 11aa,ab. 


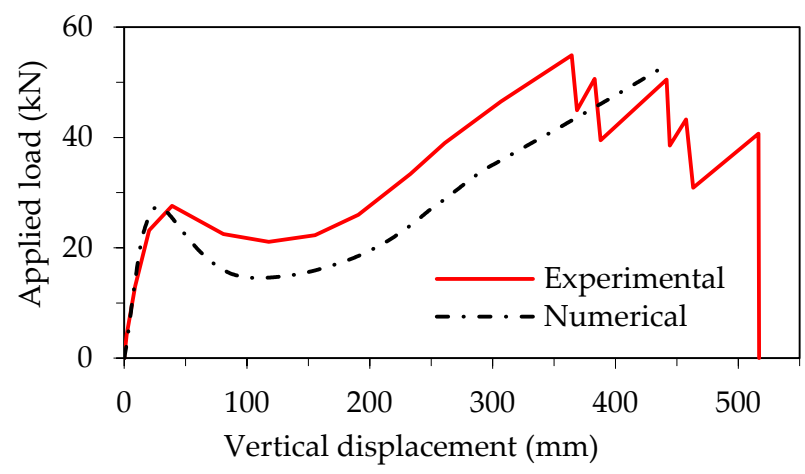

(a) specimen RCB [1]-Setup A-1/3 scale test

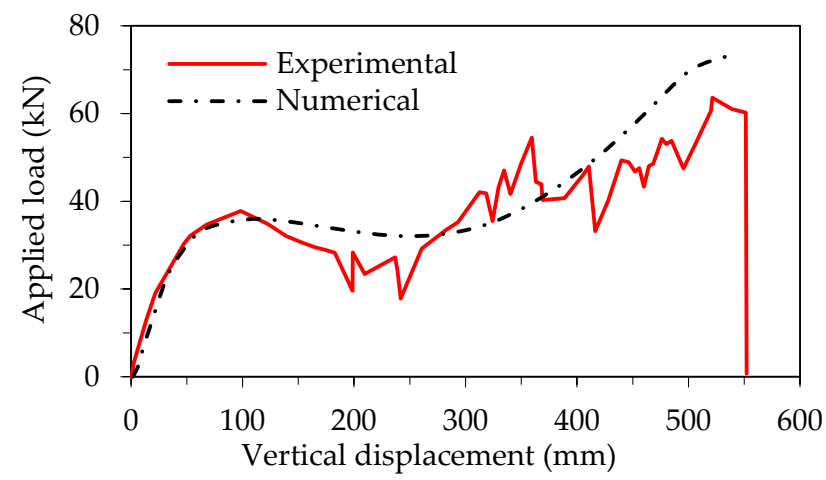

(c) specimen SS-2 [2]-Setup B-1/2 scale test

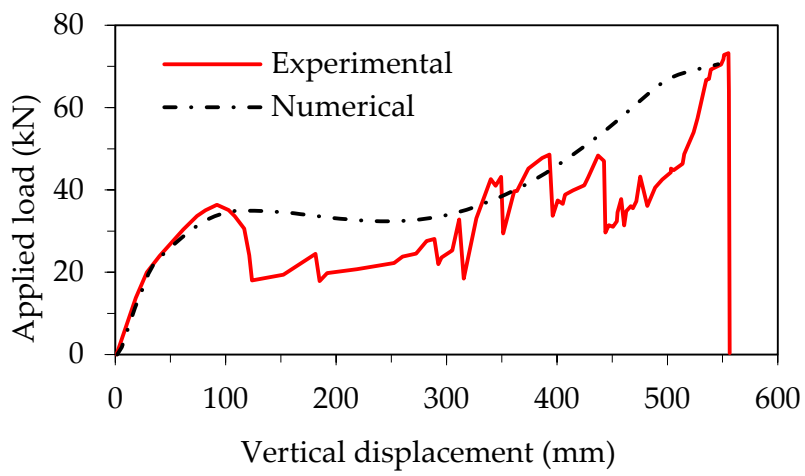

(e) specimen SS-4 [2]-Setup B-1/2 scale test

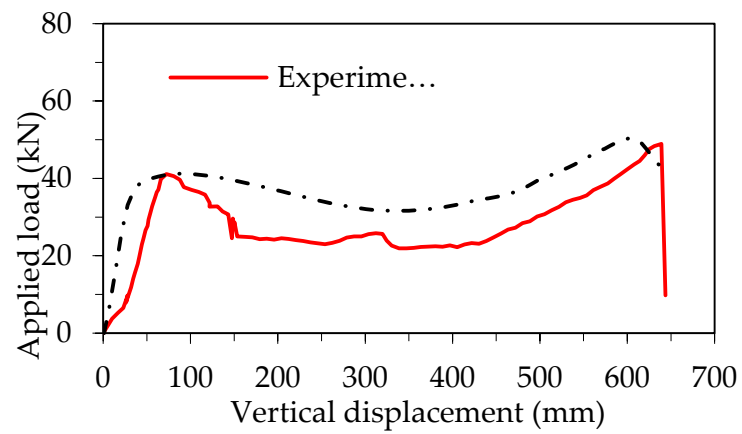

(g) specimen MJ-L-S [3]-Setup B-1/2 scale test

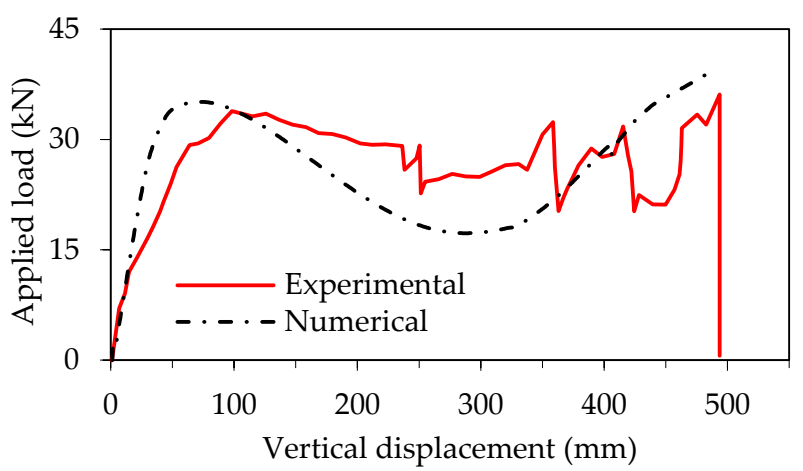

(b) specimen SS-1 [2]-Setup B-1/2 scale test

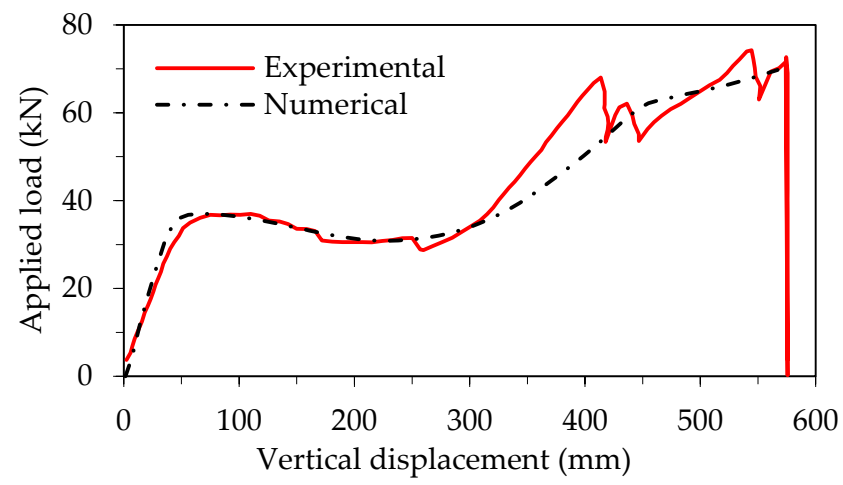

(d) specimen SS-3 [2]-Setup B-1/2 scale test

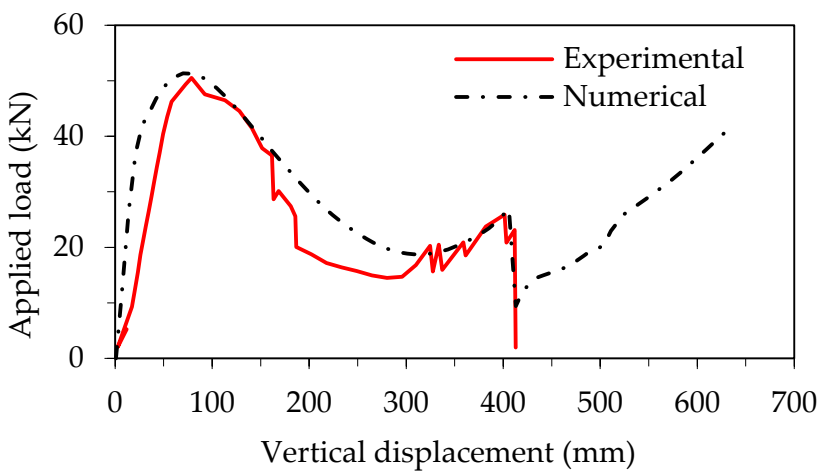

(f) specimen MJ-B-S [3]-Setup B-1/2 scale test

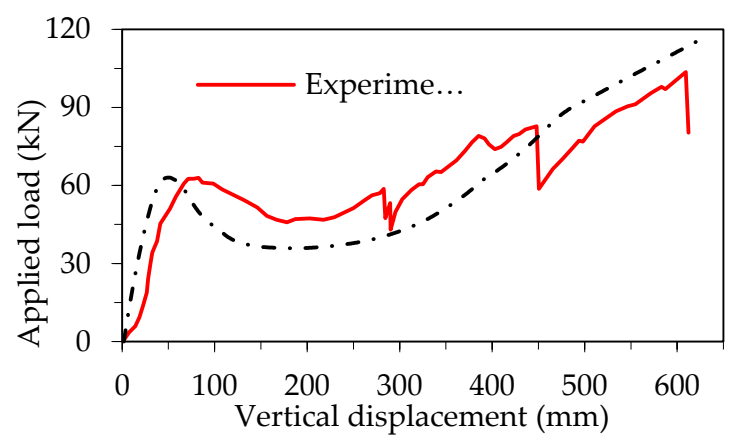

(h) specimen S4 [4]-Setup B-1/2 scale test

Figure 11. Cont. 


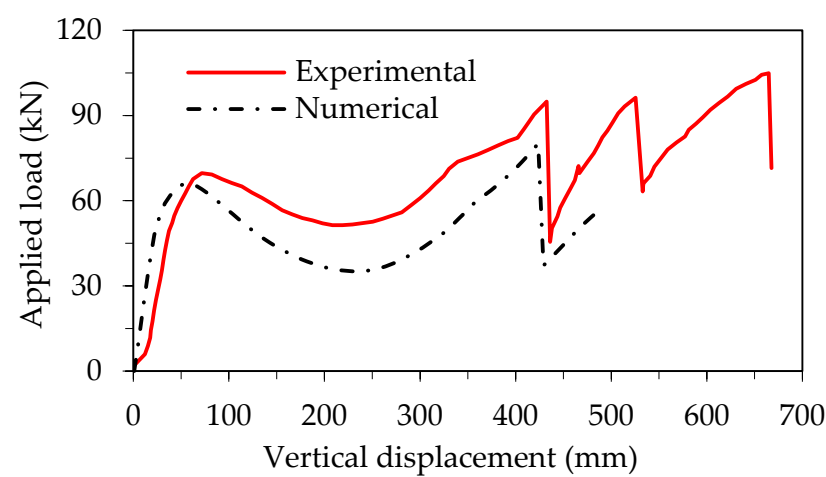

(i) specimen S5 [4]-Setup B-1/2 scale test

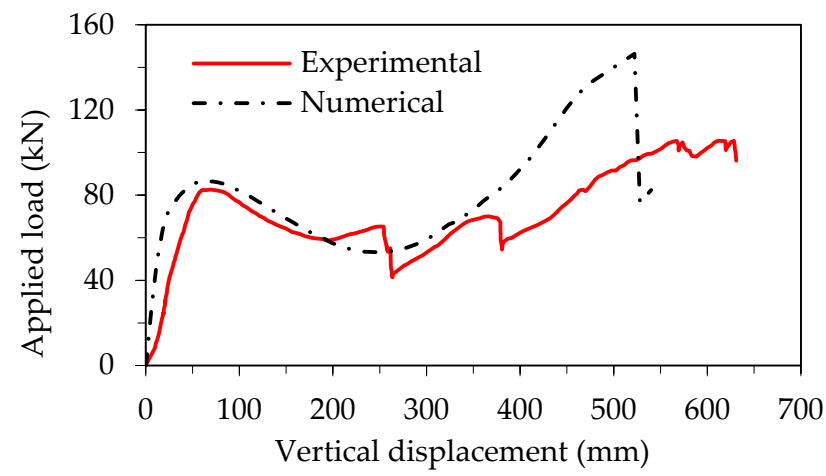

(k) specimen S7 [4]-Setup B-1/2 scale test

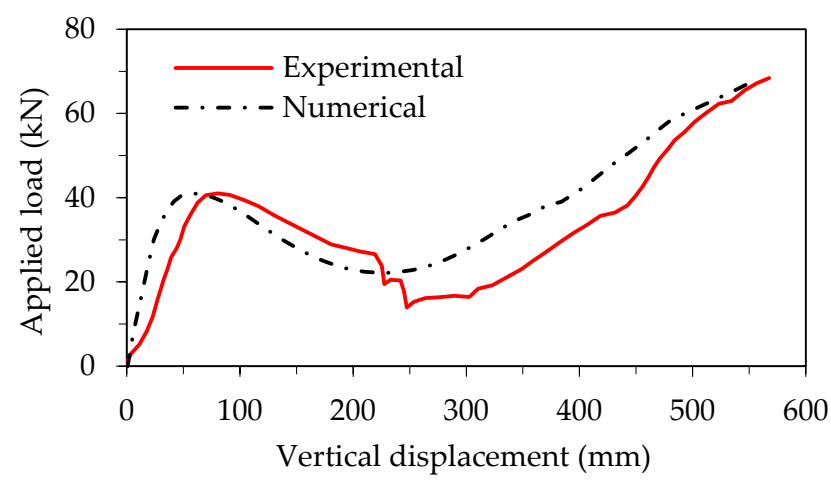

(m) specimen S1 [7]-Setup B-1/2 scale test

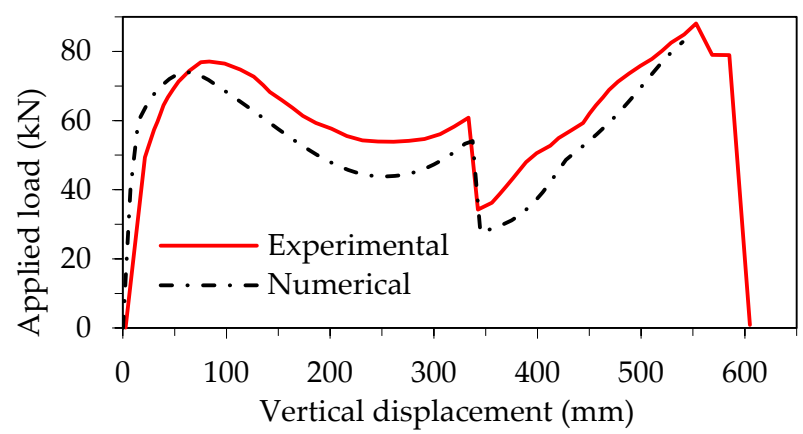

(o) specimen NSC-8 [9]-Setup B-1/2 scale test

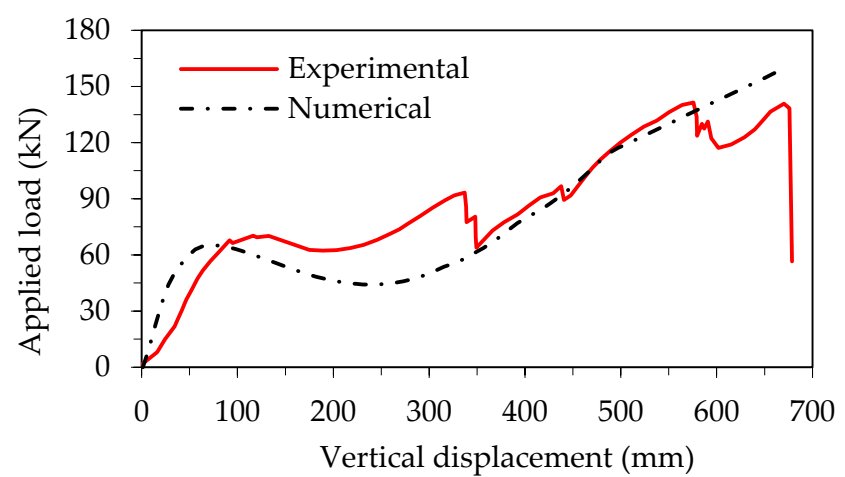

(j) specimen S6 [4]-Setup B-1/2 scale test

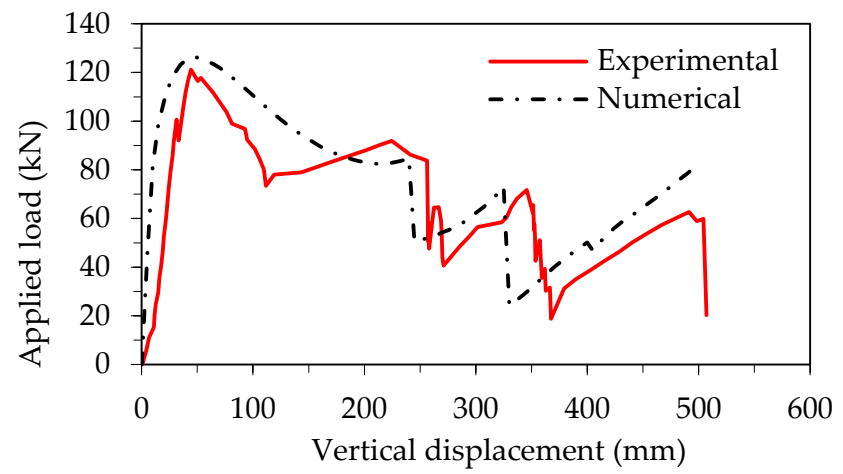

(1) specimen S8 [4]-Setup B-1/2 scale test

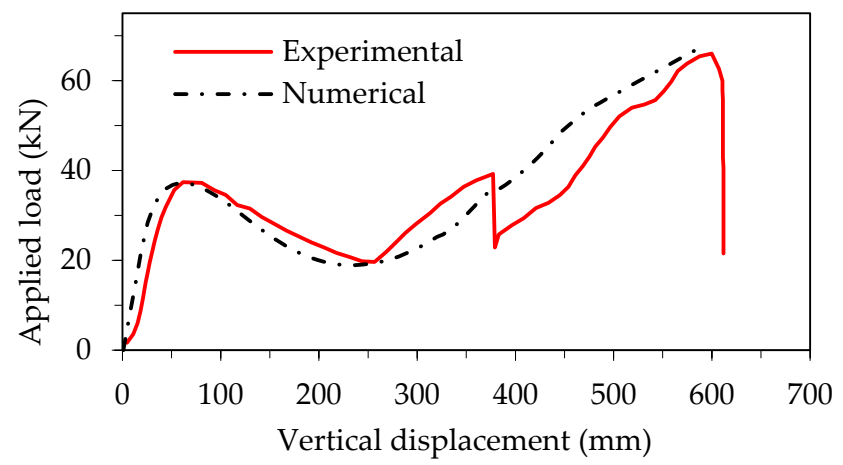

(n) specimen S2 [7]-Setup B-1/2 scale test

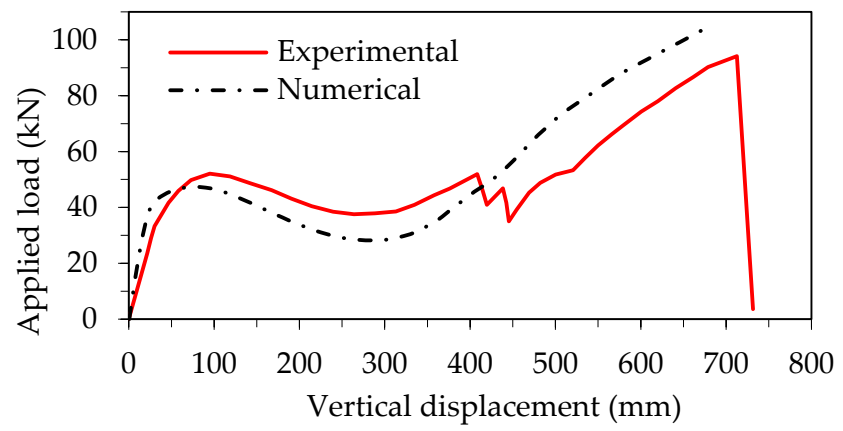

(p) specimen NSC-11 [9]-Setup B-1/2 scale test

Figure 11. Cont. 


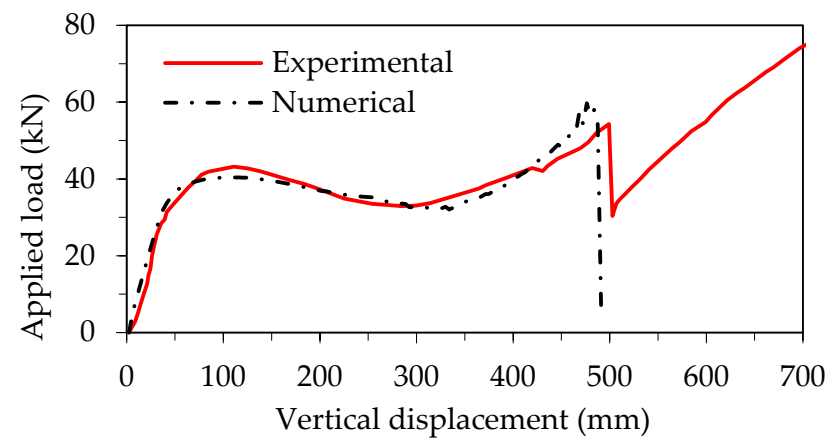

(q) specimen NSC-13 [9]-Setup B-1/2 scale test

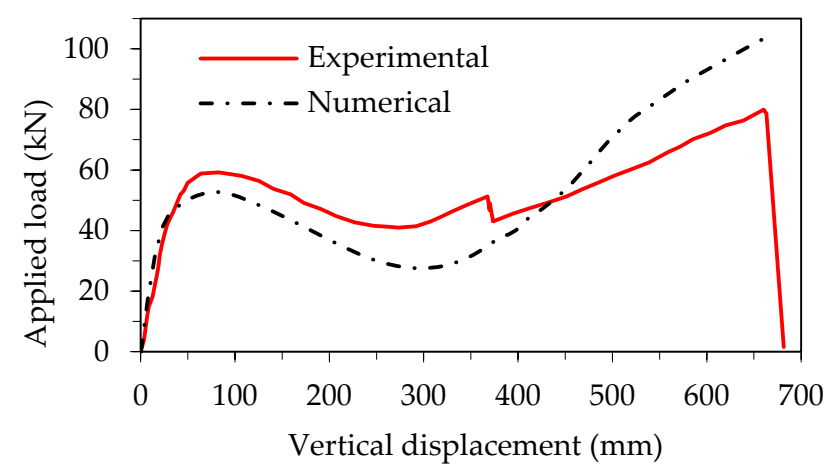

(s) specimen HSC-11 [9]-Setup B-1/2 scale test

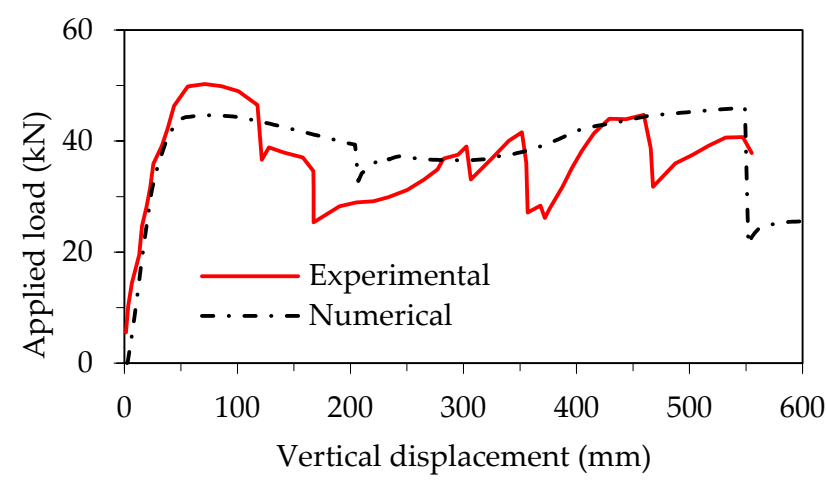

(u) specimen F1 [5]-Setup C-1/2 scale test

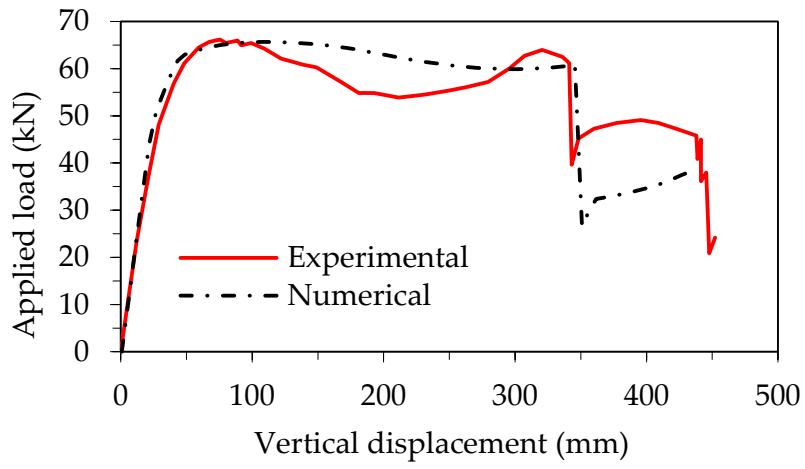

(w) specimen IF-B [8]-Setup C- $1 / 2$ scale test

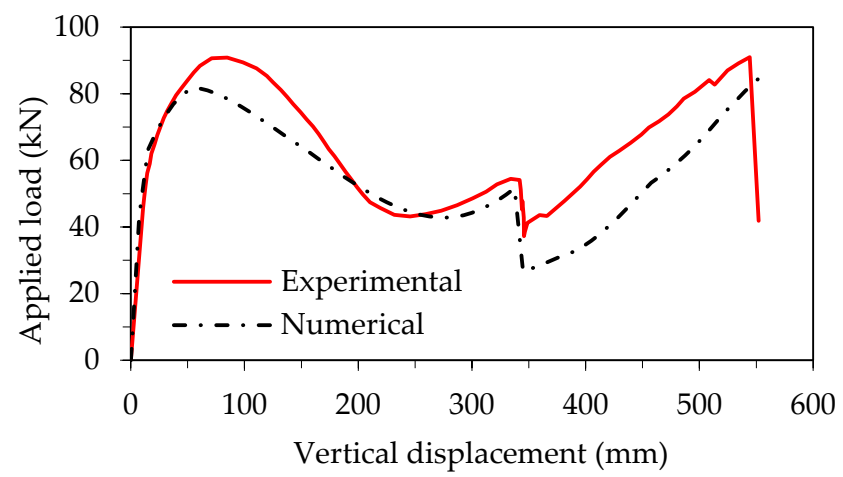

(r) specimen HSC-8 [9]-Setup B-1/2 scale test

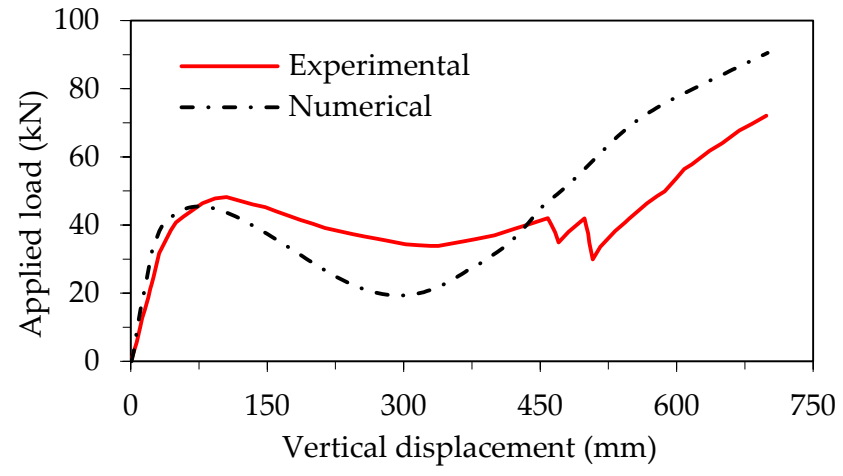

(t) specimen HSC-13 [9]-Setup B-1/2 scale test

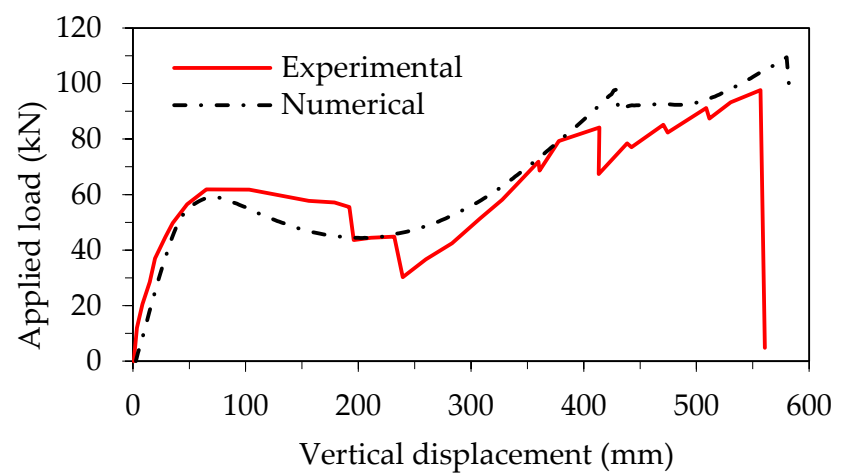

(v) specimen F2 [5]-Setup C-1/2 scale test

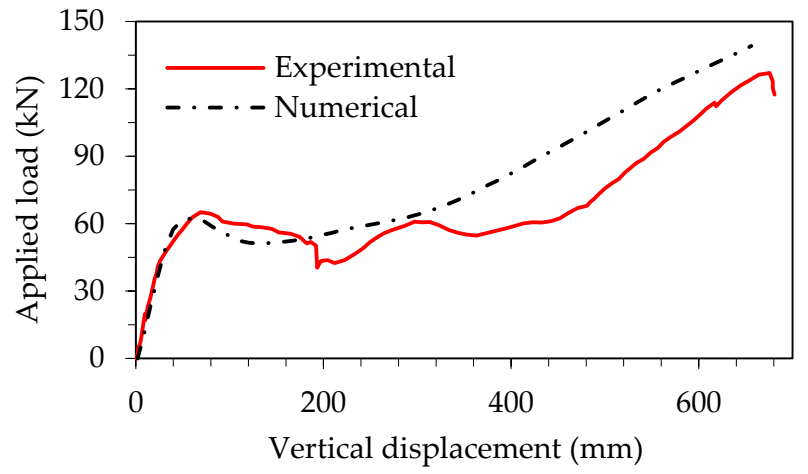

(x) specimen IF-L [8]-Setup C-1/2 scale test

Figure 11. Cont. 

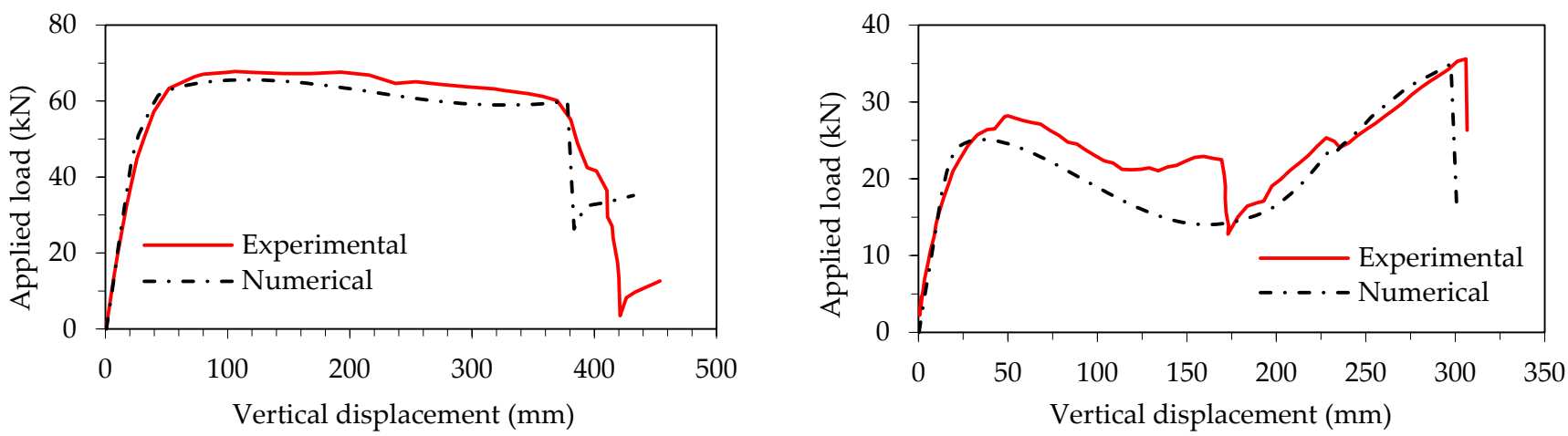

(y) specimen EF-B [8]-Setup C-1/2 scale test

(z) specimen 2D [6]-Setup D-3/10 scale test
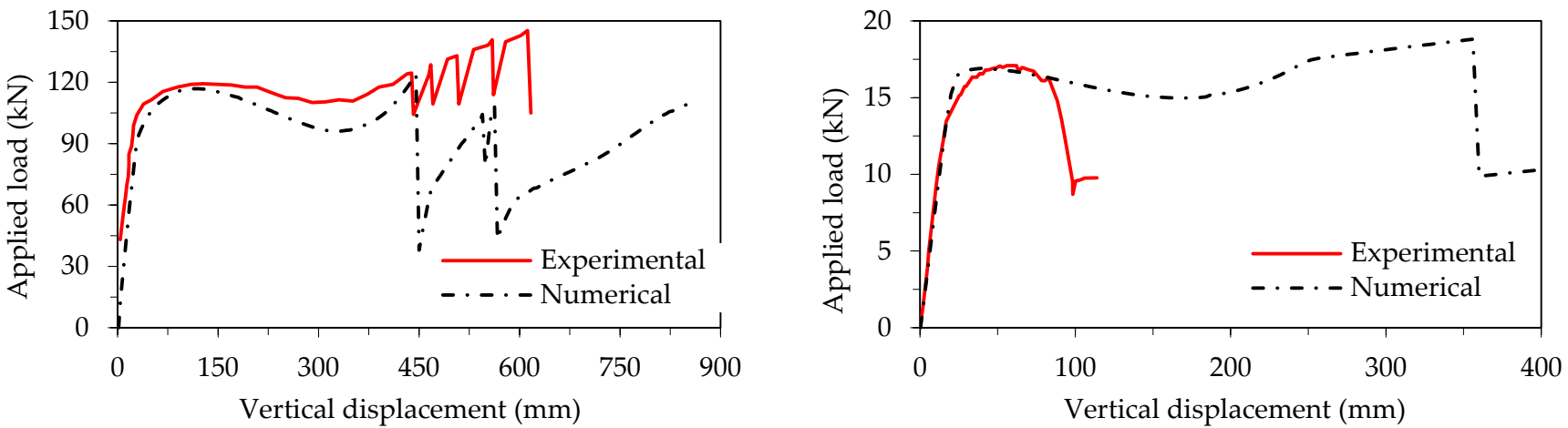

(aa) specimen RC [10]-Setup D-1/2 scale test

(ab) specimen MS [12]-Setup D-3/10 scale test

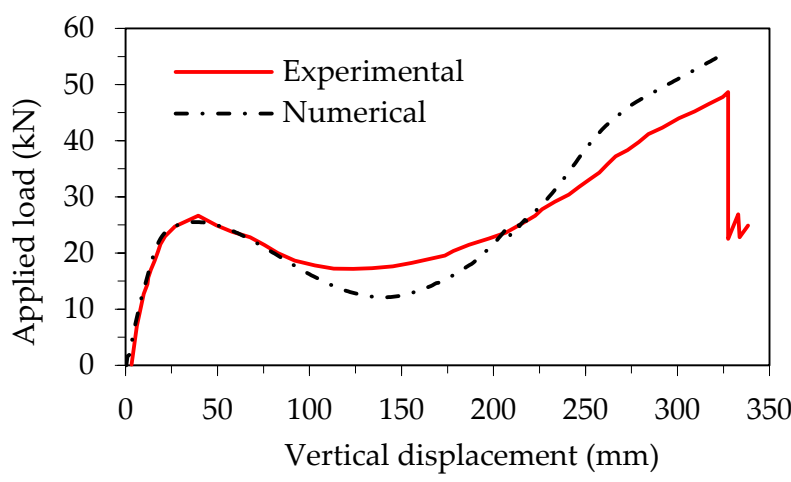

(ac) specimen Prototype [11]-Setup E-1/3 scale test

Figure 11. Test and numerical load-displacement curves for the considered twenty-nine test specimens (all displacements are measured at failed column location).

Overall, the boundary conditions in all the test setups were implemented in the model that showed a capability that could generate fairly accurate responses in comparison with the test data.

\section{Discussion}

To have a better comparison of the predicted behavior of each test specimen, this section presents the comparison of different numerically predicted key points and their corresponding test values. The key points selected for this comparison process are the initial stiffness, flexure load, displacements at flexure load, peak load, displacement at peak load, failure load, displacement at failure load, and energy, as shown in Figure 12. The figure also shows the different behavior stages of flexural action, compression arch, and tension catenary action. 


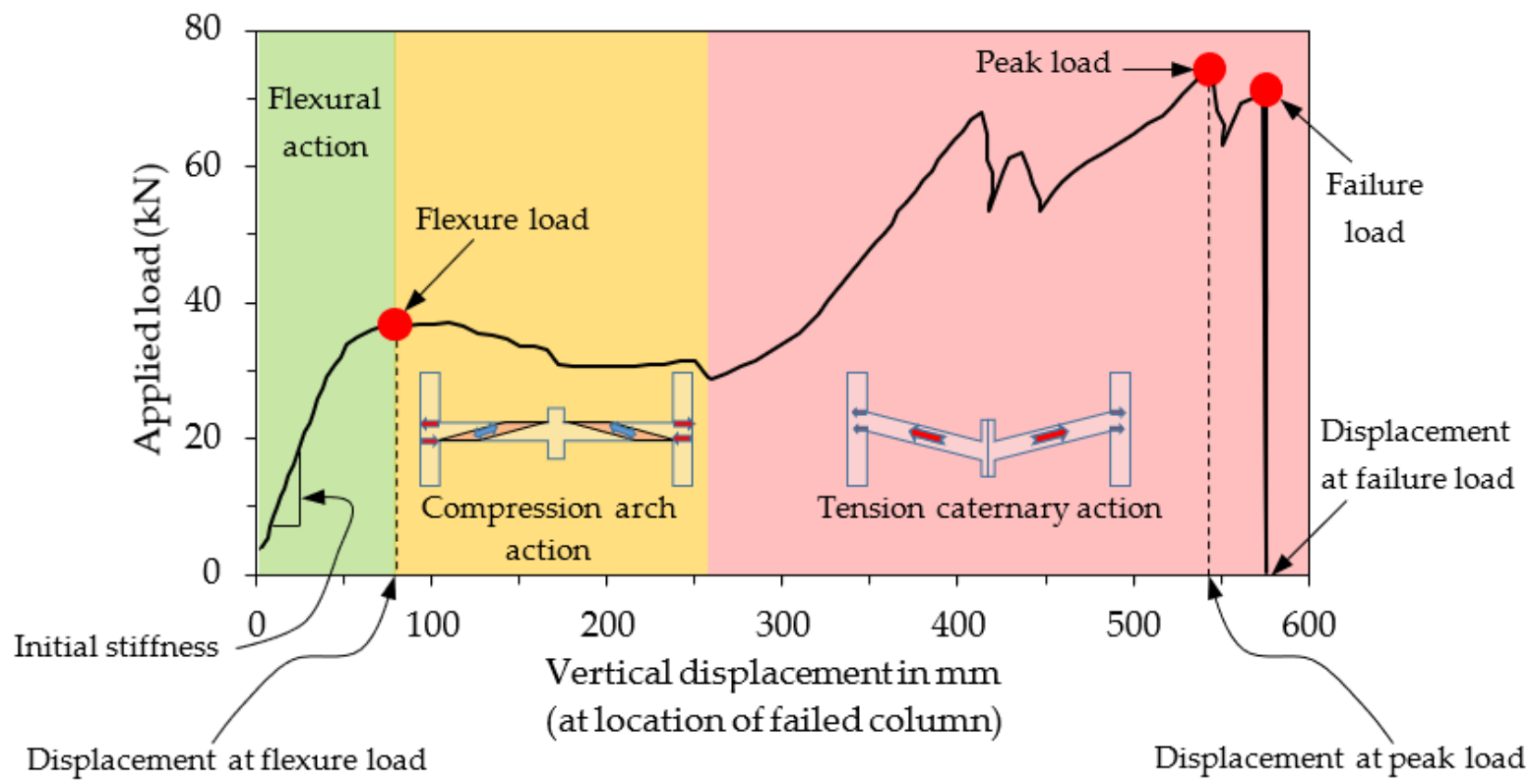

Figure 12. Selected key points for comparison (test specimen SS-3 [2]).

A total of twenty-nine data points were extracted for each property, numerical and test, and plotted in the following figures with trend lines of maximum difference of $\pm 15 \%$. A maximum difference $\pm 15 \%$ can be acceptable in progressive collapse analysis and, therefore, was considered in this study.

Figure 13a shows the comparison between the numerical and test initial stiffness for all the specimens. It is clear from Figure 13a that the proposed numerical model was capable to efficiently estimate the initial stiffness of the specimens as all the data points, except three, are within the maximum difference buffer zone of $\pm 15 \%$. Two of these three data points indicated that the model slightly over-evaluated the initial stiffness. Most of the data points that are within the buffer zone are slightly above the diagonal line indicating the initial stiffness is a little over-evaluated; nevertheless, it is still within the $15 \%$ difference.

Similarly, the evaluation of the numerical flexure loads with reference to the test values is presented in Figure 13b, which demonstrates that the proposed model accurately predicted the flexure load, since all the data points are not only well within a $\pm 15 \%$ maximum difference but also they are very close to the diagonal line.

In Figure 13c, the numerically predicted displacements at flexure load are compared with the corresponding experimentally obtained values. It is evident from the figure that there is a slight-to-moderate dispersion of the data points, some of which fell within the maximum difference of $\pm 15 \%$ while other points fell outside the maximum difference. Most of the dispersed data points indicate that the model moderately under-evaluated the displacements at flexure load for some specimens, whereas the data points within the maximum difference demonstrates that the model accurately evaluated the displacements at flexure load for the other specimens. This dispersion can be contributed to the higher numerical initial stiffness of the relevant specimens.

By the same comparison, Figure $13 \mathrm{~d}$ reveals that the proposed model accurately captured the peak load of the specimens as all the data points, except five, are within the maximum difference of $\pm 15 \%$. The five data points are slightly dispersed outside the maximum difference, where the model seemed to mostly and marginally over-predicted the peak load.

Likewise, Figure 13e discloses that the proposed model adequately predicted the displacement at peak load of the test specimens as all the data points, apart from three, fell within the maximum difference of $\pm 15 \%$. These three data points, however, are moderately spread outside the maximum difference zone and isolated between the over- and underpredicted displacements. 


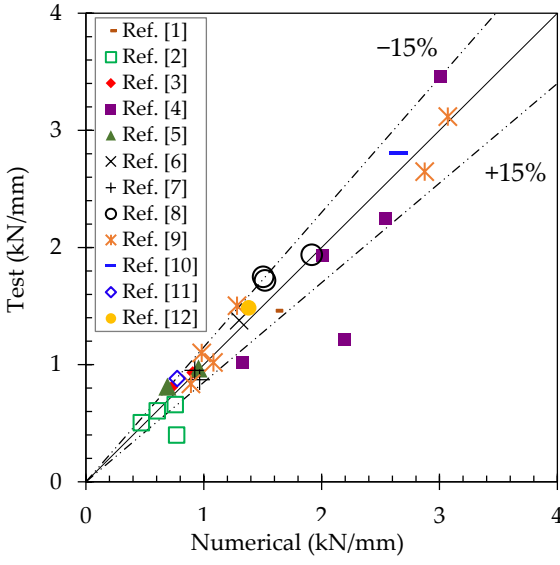

(a) initial stiffness

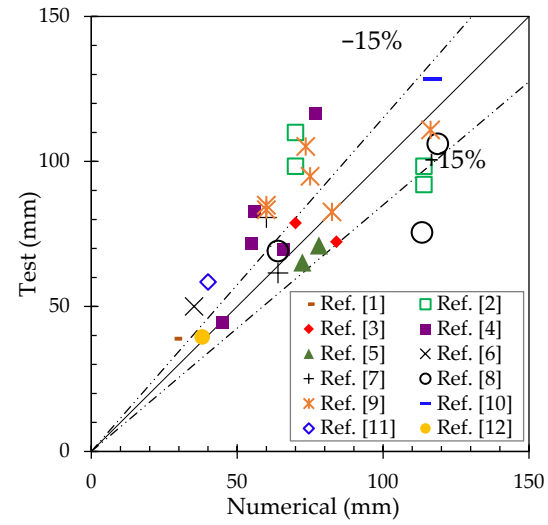

(c) displacement at flexure load

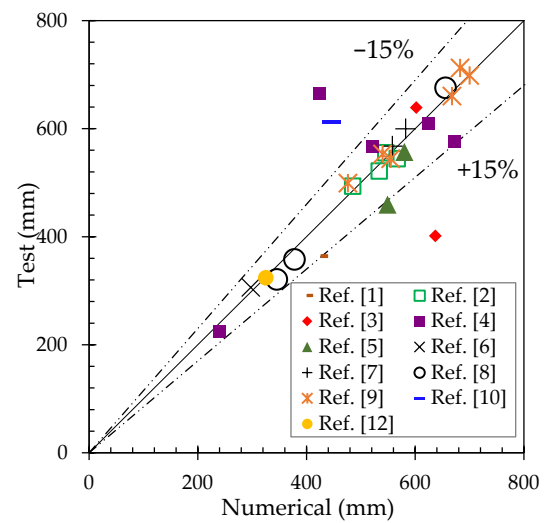

(e) displacement at peak load

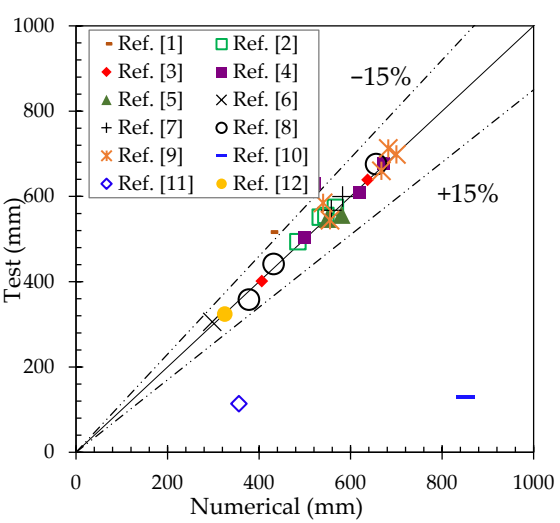

(g) displacement at failure load

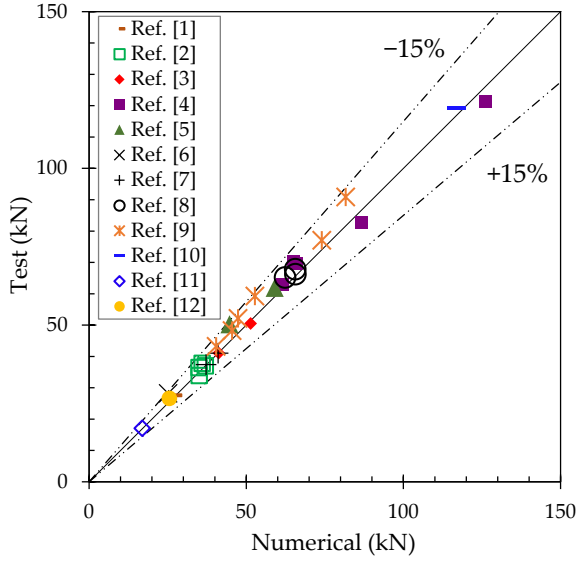

(b) flexure load

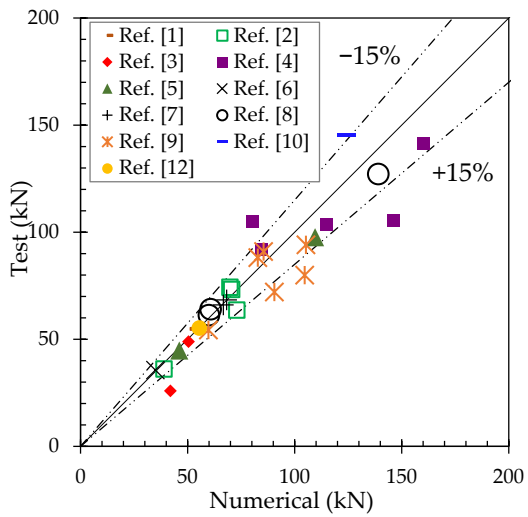

(d) peak load

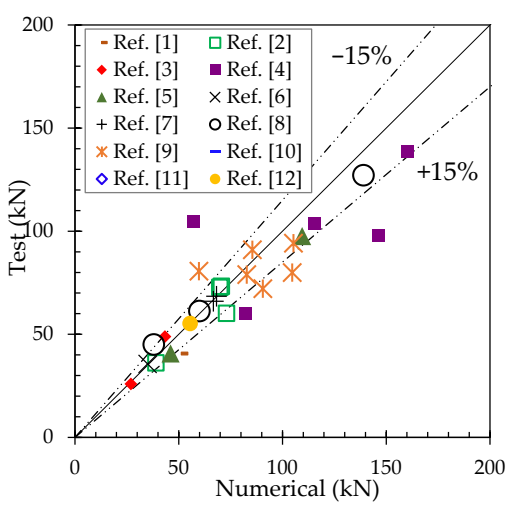

(f) failure load

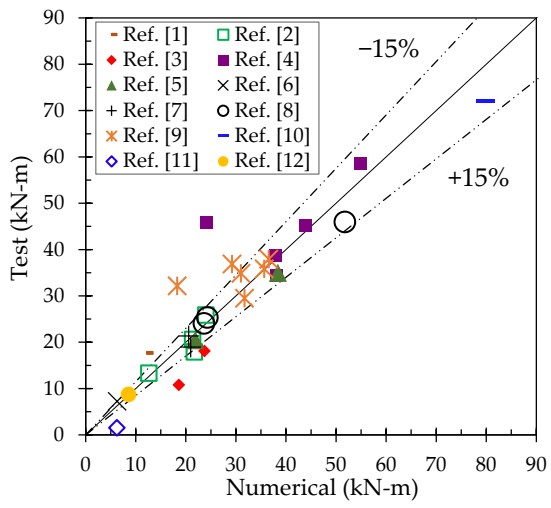

(h) total energy

Figure 13. Numerical and test comparison. 
Similar to Figure 13d, Figure 13f unveils that the numerical failure loads of the specimens were accurately evaluated by the model since all the data points, except six, are within the maximum difference of a $\pm 15 \%$ buffer zone. The six data points are slightly dispersed outside the buffer zone, where the model appeared to mostly and faintly over-predict the failure load.

Figure $13 \mathrm{~g}$ demonstrates that all the data points not only are within a $\pm 15 \%$ maximum difference but also are almost on the diagonal line, which indicate that the numerical model accurately evaluated the specimen displacements at failure load. However, two data points are away from the $15 \%$ maximum difference, indicating that the model predicted much more ductile behavior for these two specimens than their test results. In contrast, four data points are slightly dispersed due to the model marginally under-evaluating the maximum displacement of the relevant specimens.

For the predicted total energy at failure, Figure 13h exhibits that almost all the data points are within a $\pm 15 \%$ maximum difference, with some of them on the diagonal line and just a few a bit dispersed. This indicates that the numerical model can produce a reliable estimation of the total energy generated as the structure undergoes a progressive collapse due to an interior column failure.

In general, it can be concluded that the above-predicted values by the proposed model are reasonably matching with their test counterparts. The proposed model seems to be most accurate in predicting the capacity of the test specimens, i.e., ultimate load and failure load, and the total energy within $\pm 15 \%$ maximum difference trend lines. Slight to moderate dispersion away from the trend lines is observed in the predicted values of vertical displacement at the removed column location in some specimens.

\section{Conclusions}

This paper presents a numerical model based on a fiber element approach using SeismoStruct software to be utilized as a benchmark model for an accurate progressive collapse analysis of RC structures due to inner column removal. The model was based on an extensive validation process and wide parameter sensitivity analysis to accurately simulate test behaviors of twenty-nine large-scale RC sub-assemblage specimens.

A qualitative examination of the load displacement relationships and different performance criteria such as yielding of reinforcing bars, spalling and crushing of concrete, and bar rupture for twenty-nine specimens with different dimensions, material properties, reinforcement detailing, test setups, and boundary conditions, plus test scales showed a good agreement between the numerical and experimental results. This confirms the efficacy of the proposed benchmark model, which can be applied in structure progressive collapse analysis within the framework outlined in this study.

The proposed benchmark model required only seven to eleven elements to accurately simulate the test behaviors and correctly predict the different damage types and locations of the considered tests. With such a low element number, the time of analysis and computation was significantly reduced. Reducing the computation time would allow further parametric study, and using low number of elements would permit full structure 2D or 3D progressive collapse analysis with high accuracy.

The framework of the proposed model recommended key parameters such as element types, material models, number of section fibers, plastic hinge length, number of segments, and boundary conditions that best optimized the numerical simulations of the test behaviors.

The proposed model appears to be most accurate in predicting the capacity of the test specimens within $\pm 15 \%$ maximum difference trend lines. Slight discrepancies outside the trend lines were observed in the predicted values of vertical displacement at the removed column location in some specimens.

Given the costly nature of experimental research, test errors, and the lengthy testing procedure, the proposed model using SeismoStruct software can be considered as a benchmark model to accurately analyze structures under progressive collapse due to interior 
column removal. Engineers and researchers can use the model's recommended optimal key parameters that are highlighted in this study as a guide to create accurate numerical models for the progressive collapse analysis of RC structures with an internal failed column.

Author Contributions: Conceptualization, B.E.-A. and S.E.; methodology, S.E.; software, A.S.; validation, B.E.-A., S.E. and A.S.; formal analysis, B.E.-A. and S.E.; investigation, B.E.-A., S.E. and A.S.; resources, S.E. and A.S.; data curation, B.E.-A. and S.E.; writing-original draft preparation, B.E.-A.; writing-review and editing, B.E.-A.; visualization, B.E.-A. and S.E.; supervision, B.E.-A. and S.E.; project administration, B.E.-A. and S.E. All authors have read and agreed to the published version of the manuscript.

Funding: This research received no external funding.

Institutional Review Board Statement: Not Applicable.

Informed Consent Statement: Not Applicable.

Data Availability Statement: The data that support the findings of this study are available from the authors upon reasonable request.

Acknowledgments: The authors would also like to acknowledge SEiSMOSOFT for the free academic license for the SeismoStruct software.

Conflicts of Interest: The authors declare no conflict of interest.

\section{References}

1. Qiang, H.; Yang, J.; Feng, P.; Qin, W. Kinked rebar configurations for improving the progressive collapse behaviours of RC frames under middle column removal scenarios. Eng. Struct. 2020, 211, 110425. [CrossRef]

2. Alogla, K.; Weekes, L.; Augusthus-Nelson, L. A new mitigation scheme to resist progressive collapse of RC structures. Constr. Build. Mater. 2016, 125, 533-545. [CrossRef]

3. Kang, S.B.; Tan, K.H. Behaviour of precast concrete beam-column sub-assemblages subject to column removal. Eng. Struct. 2015, 93, 85-96. [CrossRef]

4. Yu, J.; Tan, K.H. Structural behavior of RC beam-column subassemblages under a middle column removal scenario. J. Struct. Eng. 2013, 139, 233-250. [CrossRef]

5. Yu, J.; Tan, K.H. Special detailing techniques to improve structural resistance against progressive collapse. J. Struct. Eng. 2014, 140, 04013077. [CrossRef]

6. Rashidian, O.; Abbasnia, R.; Ahmadi, R.; Nav, F.M. Progressive collapse of exterior reinforced concrete beam-column subassemblages: Considering the effects of a transverse frame. Int. J. Concr. Struct. Mater. 2016, 10, 479-497. [CrossRef]

7. Yu, J.; Tan, K.H. Experimental and numerical investigation on progressive collapse resistance of reinforced concrete beam column sub-assemblages. Eng. Struct. 2013, 55, 90-106. [CrossRef]

8. Kang, S.B.; Tan, K.H. Progressive collapse resistance of precast concrete frames with discontinuous reinforcement in the joint. J. Eng. Struct. 2017, 143, 04017090. [CrossRef]

9. Deng, X.F.; Liang, S.L.; Fu, F.; Qian, K. Effects of high-strength concrete on progressive collapse resistance of reinforced concrete frame. J. Eng. Struct. 2020, 146, 04020078. [CrossRef]

10. Zhou, Y.; Chen, T.; Pei, Y.; Hwang, H.J.; Hu, X.; Yi, W.; Deng, L. Static load test on progressive collapse resistance of fully assembled precast concrete frame structure. Eng. Struct. 2019, 200, 109719. [CrossRef]

11. Joshi, D.D.; Patel, P.V.; Rangwala, H.M.; Patoliya, B.G. Experimental and numerical studies of precast connection under progressive collapse scenario. Adv. Concr. Constr. 2020, 9, 235-248.

12. Ahmadi, R.; Rashidian, O.; Abbasnia, R.; Mohajeri Nav, F.; Usefi, N. Experimental and numerical evaluation of progressive collapse behavior in scaled RC beam-column subassemblage. Shock. Vib. 2016, 2016, 1-17. [CrossRef]

13. Gross, J.L.; McGuire, W. Progressive collapse resistant design J. Struct. Eng. 1983, 109, 1-15. [CrossRef]

14. Casciati, F.; Faravelli, L. Progressive failure for seismic reliability analysis. Struct. Eng. 1984, 6, 97-103. [CrossRef]

15. Sasani, M.; Werner, A.; Kazemi, A. Bar fracture modeling in progressive collapse analysis of reinforced concrete structures. Eng. Struct. 2011, 33, 401-409. [CrossRef]

16. Tsai, M.H.; Lin, B.H. Investigation of progressive collapse resistance and inelastic response for an earthquake-resistant RC building subjected to column failure. Eng. Struct. 2008, 30, 3619-3628. [CrossRef]

17. US General Services Administration. Progressive Collapse Analysis and Design Guidelines for New Federal Office Buildings and Major Modernization Projects; US General Services Administration: Washington, DC, USA, 2003.

18. Department of Defense (DoD). Design of buildings to resist progressive collapse. In Unified Facilities Criteria (UFC) 2009, 4-023-03; DoD: Washington, DC, USA, 2009. 
19. Grierson, D.E.; Xu, L.; Liu, Y. Progressive-failure analysis of buildings subjected to abnormal loading. Comput. Civ. Infrastruct. Eng. 2005, 20, 155-171. [CrossRef]

20. Mohajeri Nav, F.; Abbasnia, R.; Rashidian, O.; Usefi, N. Theoretical resistance of RC frames under the column removal scenario considering high strain rates. J. Perform. Constr. FAC 2016, 30, 04016025. [CrossRef]

21. Izzuddin, B.A.; Vlassis, A.G.; Elghazouli, A.Y.; Nethercot, D.A. Progressive collapse of multi-storey buildings due to sudden column loss-Part I: Simplified assessment framework. Eng. Struct. 2008, 30, 1308-1318. [CrossRef]

22. Powell, G. Progressive collapse: Case studies using nonlinear analysis. In Structures Congress 2005: Metropolis and Beyond; ASCE: New York, NY, USA, 2005; pp. 1-14.

23. Vlassis, A.G. Progressive Collapse Assessment of Tall Buildings. Ph.D. Thesis, Imperial College London, University of London, London, UK, 2007.

24. Marjanishvili, S.; Agnew, E. Comparison of various procedures for progressive collapse analysis J. Perform. Constr. FAC 2006, 20, 365-374. [CrossRef]

25. Alashker, Y.; El-Tawil, S. A design-oriented model for the collapse resistance of composite floors subjected to column loss. J. Constr. Steel Res. 2011, 67, 84-92.

26. Ellingwood, B.R.; Dusenberry, D.O. Building design for abnormal loads and progressive collapse. Comput-Aided Civ. Inf. 2005, 20, 194-205. [CrossRef]

27. Luccioni, B.M.; Ambrosini, R.D.; Danesi, R.F. Analysis of building collapse under blast loads. Eng. Struct. 2004, 26 , 63-71. [CrossRef]

28. Talaat, M.M. Computational Modeling of Progressive Collapse in Reinforced Concrete Frame Structures; University of California: Berkeley, CA, USA, 2007.

29. Faridmehr, I.; Osman, M.H.; Tahir, M.M.; Nejad, A.F.; Hodjati, R. Evaluation of Extreme Load Performance of Pre-Northridge Connections; GRAĐEVINAR, Journal of the Croatian Association of Civil Engineers: Zagreb, Croatia, 2014.

30. Kwasniewski, L. Nonlinear dynamic simulations of progressive collapse for a multistory building. Eng. Struct. 2010, 32, 1223-1235. [CrossRef]

31. Hao, H.; Wu, C.; Li, Z.; Abdullah, A. Numerical Analysis of Structural Progressive Collapse to Blast Loads; Tianjin University: Tianjin, China, 2006

32. Shi, Y.; Li, Z.X.; Hao, H. A new method for progressive collapse analysis of RC frames under blast loading. Eng. Struct. 2010, 32, 1691-1703. [CrossRef]

33. Elkoly, S.; El-Ariss, B. Progressive collapse evaluation of externally mitigated reinforced concrete beams. Eng. Fail. Anal. 2014, 40, 33-47.

34. Elkholy, S.; El-Ariss, B. Improving the robustness of reinforced concrete framed structures under sudden column losses. Int. J. Prot. Struct. 2016, 7, 282-300. [CrossRef]

35. Elkholy, S.; El-Ariss, B. Enhanced external progressive collapse mitigation scheme for RC structures. Int. J. Struct. Eng. 2016, 7, 63-88. [CrossRef]

36. Elkholy, S.; El-Ariss, B. Increasing Robustness of Reinforced Concrete Structures under Column Losses Scenario. In Proceedings of the 9th International Structural Engineering and Construction Conference, ISEC_09, Valencia, Spain, 24-29 July 2017.

37. El-Ariss, B.; Elkholy, S.A. Scheme for beam progressive collapse mitigation. Int. J. Struct. Eng. 2018, 9, 175-190. [CrossRef]

38. Shehada, A.; Elkholy, S.; El-Ariss, B. Numerical Progressive Collapse Analysis of RC Framed Structures. In Proceedings of the 6th World Congress on Civil, Structural, and Environmental Engineering, Virtual, 21-23 June 2021; pp. 1-8.

39. Brunesi, E.; Nascimbene, R. Extreme response of reinforced concrete buildings through fiber force-based finite element analysis. Eng. Struct. 2014, 69, 206-215. [CrossRef]

40. Sousa, R.; Bianchi, F.; Pinho, R.; Nascimbene, R.; Kazantzidou, D. Modelling issues on seismic assessment of irregular RC structures. In Proceedings of the International Conference on Computational Methods in Structural Dynamics and Earthquake Engineering (COMPDYN 2011), Corfu, Greece, 26-28 May 2011.

41. SeismoStruct 2021-A Computer Program for Static and Dynamic Nonlinear Analysis of Framed Structures. Available online: https:/ / seismosoft.com/ (accessed on 1 November 2021).

42. Prota, A.; Cicco, F.; Cosenza, E. Cyclic behavior of smooth steel reinforcing bars: Experimental analysis and modeling issues. $J$. Earthq. Eng. 2009, 13, 500-519. [CrossRef]

43. Madas, P.; Elnashai, A.S. A new passive confinement model for transient analysis of reinforced concrete structures. Earthq. Eng. Struct. Dyn. 1992, 21, 409-431. [CrossRef] 